\title{
ENDOWMENT EFFECTS WITHIN CORPORATE AGENCY RELATIONSHIPS
}

\author{
JENNIFER ARLEN, MATTHEW SPITZER, and ERIC TALLEY*
}

\begin{abstract}
Behavioral economics is an increasingly prominent field within corporate law scholarship. A particularly noteworthy behavioral bias is the "endowment effect"- the observed differential between an individual's willingness to pay to obtain an entitlement and her willingness to accept to part with one. Should endowment effects pervade corporate contexts, they would significantly complicate much common wisdom within business law, such as the presumed optimality of ex ante agreements. Existing research, however, does not adequately address the extent to which people manifest endowment effects within agency relationships. This article presents an experimental test for endowment effects for subjects situated in an agency relationship that typifies many firms. We find that subjects do not exhibit significant endowment effects. An additional experimental test suggests that this finding may be largely due to framing: subjects situated as "agents" may view entitlements principally in terms of exchange value, thereby dampening endowment.
\end{abstract}

\section{INTRODUCTION}

B EHavioral law and economics (BLE) has risen to prominence of late within legal scholarship. Its ascension is due-at least in part-to its aim of

* Jennifer Arlen is Ivadelle and Theodore Johnson Professor of Law and Business, University of Southern California Law School, and Visiting Professor of Law, Yale Law School; Matthew Spitzer is Dean and Carl Mason Franklin Professor of Law, University of Southern California Law School; and Eric Talley is Professor of Law, University of Southern California Law School, and Visiting Professor of Law, California Institute of Technology. For helpful comments, we thank Scott Altman, Ian Ayres, Linda Babcock, Omri Ben-Shahar, Colin Camerer, Bill Carney, Rachel Croson, Sam Fraidin, Michal Gal, Rafael Gely, Henry Hansmann, Elizabeth Hoffman, D. Bruce Johnson, Dan Kahan, Ed Kitch, James Konow, Russell Korobkin, Lewis Kornhauser, Don Langevoort, Tom Lyon, Ed McCaffery, Eric Posner, Jeffrey Rachlinski, Uriel Procaccia, Mark Ramseyer, Susan Rose-Ackerman, Dan Simon, and Lynn Stout. We also thank participants at workshops at American University; Boalt Hall; the University of Cincinnati; Cornell University; Duke University; Fried, Frank, Harris, Shriver \& Jacobson; University of the Pacific, McGeorge School of Law; New York University; the University of Michigan; the University of Miami; Stanford University; the University of Southern California; the University of Virginia; the University of Texas (Graduate School of Business); the 2001 USC/Caltech Conference on Behavioral Law, Economics and Organizations; the 2000 annual meeting of the American Law and Economics Association; the 2000 UCLA Conference on Cognition, Emotion and Rational Choice; and the 1999 UCLA Law School Conference on Corporate Governance. This research was funded in part by a grant from the National Science Foundation (NSF) (grant SBR 973081). The views expressed herein are solely those of the authors and do not represent the views of the NSF.

[Journal of Legal Studies, vol. XXXI (January 2002)]

(C) 2002 by The University of Chicago. All rights reserved. 0047-2530/2002/3101-0001\$01.50 
unifying two historically distinct analytic paradigms: economics and psychology. While embracing the conventional economic premise that legal rules embody behavior-altering incentives, BLE nevertheless disengages from neoclassical economic theory, positing an account of human behavior in which people display numerous systematic, cognitive biases that are at variance with the predictions of rational choice theory.

Behavioral law and economics has fostered renewed academic skepticism about central tenets of law and economics that depend on strong rationality assumptions. ${ }^{1}$ This skepticism poses an important challenge to conventional corporate law scholarship, much of which is premised on the Coasean prediction that-in the absence of significant externalities, information asymmetries, or garden-variety transaction costs-the law can (and should) defer to the attempts of private parties to allocate rights and obligations optimally. ${ }^{2}$ This prediction leads naturally to the prescription that corporate law should generally avoid imposing immutable (or "mandatory") rules, except when necessary to address conventional market failures, and thus should be primarily confined to two tasks: (i) providing default rules that most rational corporate stakeholders would tend to favor ex ante and (ii) providing doctrines for interpreting parties' endeavors to contract around the default rules. ${ }^{3}$ By casting doubt on the accuracy of strong rationality assumptions, BLE raises the serious possibility that, notwithstanding market failures, privately negotiated organizational relationships systematically diverge from efficiency. And, if such deviations are persistent, then the normative case for mandatory regulation is significantly larger than the conventional economic approach suggests-resting not only on previously articulated market-failure considerations but also on some form of measured paternalism. ${ }^{4}$

\footnotetext{
' For informative reviews of this literature, see Donald C. Langevoort, Behavioral Theories of Judgment and Decisionmaking in Legal Scholarship: A Literature Review, 51 Vand. L. Rev. 1499 (1998); Christine Jolls, Cass R. Sunstein, \& Richard Thaler, A Behavioral Approach to Law and Economics, 50 Stan. L. Rev. 1471 (1998); Behavioral Law and Economics (Cass R. Sunstein ed. 2000).

${ }^{2}$ See R. H. Coase, The Problem of Social Cost, 3 J. Law \& Econ. 1 (1960).

${ }^{3}$ See, for example, Frank H. Easterbrook \& Daniel R. Fischel, The Economic Structure of Corporate Law (1991); Symposium: Contractual Freedom in Corporate Law, 89 Colum. L. Rev. 1395 (1989). For a variation on this theme, see Ian Ayres \& Robert Gertner, Strategic Contractual Inefficiency and the Optimal Choice of Legal Rules, 101 Yale L. J. 729 (1992), and Eric Talley, Turning Servile Opportunities into Gold: A Strategic Analysis of the Corporate Opportunities Doctrine, 108 Yale L. J. 277 (1998).

${ }^{4}$ Recent efforts discussing the relevance of BLE for corporate law or securities law include Stephen M. Bainbridge, Mandatory Disclosure: A Behavioral Economic Analysis of Mandatory Disclosure, 68 U. Cincinnati L. Rev. 1023 (2000); Margaret M. Blair \& Lynn A. Stout, Trust, Trustworthiness, and the Behavioral Foundations of Corporate Law, 149 U. Penn. L. Rev. 1735 (2001); James Cox \& Harry Munsinger, Bias in the Boardroom: Psychological Foundations and Legal Implications of Corporate Cohesion, 48 Law \& Contemp. Probs. 83 (1985); Robert Haft, Business Decisions by the New Board: Behavioral Science and Corporate Law, 80 Mich. L. Rev. 1 (1981); Henry Hu, Risk, Time, and Fiduciary Principles in Corporate Investment, 38 UCLA L. Rev. 277 (1990); Donald C. Langevoort, Organized Illusions: A Behavioral Theory
} 
Although BLE spotlights a number of nonrational biases, one that has particular relevance for corporate scholarship is the frequently observed divergence between willingness to pay (WTP) and willingness to accept (WTA). While rational actor models generally assume that mere ownership or possession of an asset does not influence an individual's valuation of it (once one controls for wealth and income effects), an increasing body of empirical and experimental evidence demonstrates the opposite. Specifically, the maximum amount a nonowner would be willing to pay for an entitlement is often significantly less than the minimum amount she would demand to part with it if she initially owned it. This divergence between willingness to pay and willingness to accept has become known as the "endowment effect."

The presence of endowment effects within firms would have important implications for legal rules governing business organizations. As noted above, it would undermine the premise of the Coase theorem that free, fully informed, ex ante bargains necessarily result in the efficient distribution of property rights. Rather, an entitlement may remain "stuck" with its initial owner, even though another would value the entitlement more were she endowed with it initially. ${ }^{6}$ As applied to corporate scholarship, endowment effects undercut the widespread presumption that a "nexus of contracts" entered into voluntarily by informed parties is presumptively welfare maximizing, both immediately before and after execution. Indeed, this presumption leans heavily on preference stability - assuming that initial possession does not affect valuation. When, in contrast, endowment does affect valuation, the agreements people enter into before they become endowed will not inevitably maximize joint welfare immediately upon becoming endowed. ${ }^{7}$ Such

of Why Corporations Mislead Stock Market Investors (and Cause Other Social Harms), 146 U. Penn. L. Rev. 101 (1997); Donald C. Langevoort, Selling Hope, Selling Risk: Some Lessons for Law from Behavioral Economics about Stockbrokers and Sophisticated Customers, 84 Cal. L. Rev. 627 (1996); Lawrence E. Mitchell, Trust and Team Production in Cost-Capitalist Society, 24 J. Corp. L. 869 (1999).

${ }^{5}$ See generally Richard Thaler, The Winner's Curse: Paradoxes and Anomalies of Economic Life 63-78 (1992).

${ }^{6}$ See Elizabeth Hoffman \& Matthew Spitzer, Willingness to Pay vs. Willingness to Accept: Legal and Economic Implications, 71 Wash. U. L. Q. 59, 99 (1993); Daniel Kahneman, Jack Knetsch, \& Richard Thaler, Experimental Tests of the Endowment Effect and the Coase Theorem, 98 J. Pol. Econ. 1325 (1990). Indeed, the endowment effect undermines-or at least complexifies-the concept of social welfare itself, making it difficult to define the cost and benefit of reallocating an entitlement. See Hoffman \& Spitzer, supra, at 103-12; see also Edward J. McCaffery, Daniel J. Kahneman, \& Matthew L. Spitzer, Framing the Jury: Cognitive Perspectives on Pain and Suffering Awards, 81 Va. L. Rev. 1341 (1995).

${ }^{7}$ The endowment effect is particularly likely to have an adverse effect on bargaining if, as evidence suggests, buyers and sellers do not fully anticipate the effect on either themselves or others. See George Loewenstein \& Daniel Adler, A Bias in the Prediction of Tastes, 105 Econ. J. 929 (1995) (suggesting that people do not anticipate their own endowment effects); Leaf Van Boven, David Dunning, \& George Loewenstein, Trading Places: Egocentric Empathy Gaps between Others and Buyers (unpublished manuscript, Dep't Soc. \& Decision Sciences, Carnegie Mellon Univ. 2000) (suggesting owners and buyers overestimate the similarity between their own valuation of an objects and that of others). 
a finding would have obvious implications for corporate law, since corporate governance agreements are often executed prior to endowment and yet govern the parties' relationship subsequent to one (or more) parties becoming endowed. ${ }^{8}$ Thus, unanticipated endowment effects might undercut the existing rationale behind judicial deference toward corporate charters over later governance agreements (such as bylaws, collective bargaining agreements, and shareholder proposals). ${ }^{9}$ In addition, unanticipated endowment effects in managerial positions might provide insight into why managers of public corporations agree in good faith to charters that do not contain takeover defenses, only to seek the subsequent implementation of such defenses. ${ }^{10}$

While widespread endowment effects clearly would have important implications for corporate law, any serious effort to incorporate endowment effects into normative policy prescriptions must contend with a problem of domain uncertainty. Existing evidence on the endowment effect suggests that it is pronounced in certain circumstances yet muted (or absent) in others. Much like other deviations from rational choice, the existence and magnitude of the endowment effect is context dependent. ${ }^{11}$ Moreover, neither theory nor existing experimental evidence yields robust predictions as to whether people will manifest the endowment effect within business organizations. Thus, before commencing with normative or prescriptive theories based on the endowment effect, it is important first to ascertain whether (and to what extent) the phenomenon operates within business organizations.

This article provides an experimental test of whether the endowment effect affects individual choices within business agency relationships, that is, the "principal-agent" relationships that populate many business organizations. ${ }^{12}$ Specifically, we modify the classic endowment effect experiments to determine whether subjects situated in a business agency context display endow-

\footnotetext{
${ }^{8}$ Of course, a normative utilitarian analysis allowing for endogenous preferences thus must specify a time frame at which welfare-relevant preferences are deemed to "matter" (for example, pre- or postendowment). For reasons that will become obvious, we need not take a position on this debate in this article.

${ }^{9}$ Similarly, in the employment area, scholars have argued that endowment effects undermine the presumed validity of employment at will, on the grounds that, ex ante, employees voluntarily agree to an at-will employment relationship only because they fail to anticipate that, once employed, they will endow their positions and thus value them more. Samuel Issacharoff, Contracting for Employment: The Limited Return of Common Law, 74 Texas L. Rev. 1783, 1800-1803 (1996); see Cass R. Sunstein, Human Behavior and the Law of Work, 87 U. Va. L. Rev. 205 (2001) (arguing in the context of at-will doctrines that "[s]o long as the right is initially allocated to one or another side, an endowment effect cannot be avoided").

${ }^{10}$ See John C. Coates IV \& Guhan Subramanian, A Buy-Side Model of M\&A Lockups: Theory and Evidence, 53 Stan. L. Rev. 307, 362-64 (2000) (arguing that the bidder's manager's endowment effect in the target may partially explain lock-ups).

"See, generally, Jennifer Arlen, The Future of Behavioral Economic Analysis of Law, 51 Vand. L. Rev. 1765, 1777-81 (1998); Cass R. Sunstein, Behavioral Analysis of Law, 64 U. Chi. L. Rev. 1175, 1180 (1997).

${ }^{12}$ To be sure, legal rules regulate many types of agency problems, but we concentrate solely on the canonical "employer-employee" relationship within firms.
} 
ment effects in contracting with their employer. This is, to our knowledge, the first test of whether agents manifest an endowment effect in exchanges with their employers. ${ }^{13}$

Our central finding is that situating subjects in an agency context significantly dampens the magnitude (and perhaps even the existence) of the endowment effect. Specifically, although our control subjects manifested an endowment effect similar to that detected in prior literature, our agency subjects manifested virtually no endowment effect whatsoever. This result holds even when we control for demographic differences among subjects.

We then conducted an experiment to assess why agency relationships mute the endowment effect. The existing evidence supports two distinct hypotheses: (1) the agency relationship may cause subjects to focus on the exchange value of the asset, as opposed to its use value (which should mute endowment effects given evidence that subjects typically fail to manifest the effect for entitlements they hold primarily for exchange purposes), or (2) the agency relationship may mute endowment effects if agents exhibit other-regarding preferences toward the firm that cause them to disendow their own assets when needed by the firm. As our initial agency experiment design implicates both of these possibilities, we ran a second agency experiment designed to incorporate exchange-value concerns alone, without suggesting that subjects' actions could affect firm value. Again, we found no statistically significant evidence of an endowment effect. These results not only are consistent with the findings of our initial agency experiment but also suggest that the business context itself induced subjects to focus on the exchange value of the asset, thereby eliminating any statistically significant endowment effect.

Our results have both specific and general implications. Most directly, they counsel a degree of caution for those involved in developing normative policy prescriptions for corporate or employment law based on endowment effects. More generally, our results underscore an important tension between contextspecific experimental research and broad-based normative inquiries, highlighting the need for experimental inquiries targeted to each specific policy domain.

Nevertheless, while we did not find evidence of an endowment effect in a corporate agency context, this does not imply that corporate scholars can ignore behavioral economics altogether. On the contrary, considerable evidence remains that certain cognitive biases profoundly affect some agency

\footnotetext{
${ }^{13}$ Previous analysis has shown that agents do not manifest endowment effects when acting on behalf of their principal in exchanges involving the principal's assets. See James D. Marshall, Jack L. Knetsch, \& J. A. Sinden, Agents' Evaluations and the Disparity in Measures of Economic Loss, 7 J. Econ. Behav. \& Org. 115 (1986). This could arise because agents fail to anticipate their principals' endowment effects. See also Leaf van Boven, George Loewenstein, \& David Dunning, Biased Predictions of Others' Tastes: Underestimations of Owners' Selling Prices by "Buyers Agents," J. Econ. Behav. \& Org. (forthcoming 2002). By contrast, we examine agents' behavior when they contract on their own behalf.
} 
relationships. Thus, increased attention to cognitive biases by corporate scholars seems prudent, if accompanied by both a prudent dose of caution and, ideally, more experimental research in the area. ${ }^{14}$ Along these same lines, it is important to note that our analysis is largely limited to agency relationships that resemble the employer-employee relationship. In other types of agency relationship, the endowment effect may well resurface with significant force.

Our discussion consists of three parts. Section II reviews the empirical evidence and theories underlying the endowment effect, focusing on current literature. Section III describes our control and initial agency experiments and presents our results. Section IV presents the results of our "exchangevalue" agency experiment, positing some implications that may flow therefrom.

\section{Endowment Effects: Existing Theory and Evidence}

This section reviews the existing evidence on the endowment effect to assess its implications for corporate law scholarship. The evidence suggests that people manifest the effect in a number of different circumstances, including in certain market settings. Nevertheless, both theory and evidence present reasons to expect that corporate participants (employees, managers, and shareholders) might not generally manifest this effect in their intrafirm exchanges.

\section{A. Evidence of the Endowment Effect}

A vast experimental and theoretical literature exists documenting the endowment effect. Perhaps the most cited experiment demonstrating the endowment effect involved Cornell University coffee mugs, which sold at the nearby university bookstore for approximately $\$ 6$ (as was indicated by price tags on the bottom of the mug). ${ }^{15}$ The experimenters randomly distributed the mugs to half of their subjects. Each participant was then told that she could sell/buy a mug by stating a sale/purchase price, which was then given to the experimenters. The experimenters then determined the market-clearing price, and all those who made offers equal to or below/above that price participated in an exchange.

Economic theory predicts that since the mugs were distributed randomly, half the mugs would trade, moving from those who valued mugs less to those who valued them more. In fact, few mugs traded, which suggests that on average those endowed with the mugs valued them significantly more than those who were not endowed. Indeed, while the median buyer was not willing to pay more than $\$ 2.25-\$ 2.75$ to purchase the mug, the median seller

\footnotetext{
${ }^{14}$ See, for example, sources in note 80 infra, and the literature discussed in Donald $\mathrm{C}$. Langevoort, Organized Illusions, supra note 4.

${ }^{15}$ See Kahneman, Knetsch, \& Thaler, supra note 6.
} 
required $\$ 5.25$ to part with her mug. Thus, in apparent contrast with rational choice theory, evidence suggested that each mug owner came to value the mug more simply because she now owned it. ${ }^{16}$

Efforts to discredit the basic endowment effect result have largely failed. ${ }^{17}$ Indeed, experimental evidence of the effect has now transcended numerous experimental settings, using a variety of items-such as coffee mugs, chocolate bars, and pens-as well as subjects from different countries. ${ }^{18}$ The endowment effect also persists when subjects are repeat players within the experiment. ${ }^{19}$ Similarly, empirical studies of real-world exchanges also reveal evidence of an endowment effect. ${ }^{20}$ Thus, the endowment effect appears to be a genuine phenomenon and not simply the product of faulty experimental design.

\section{B. Scope of the Endowment Effect}

Existing evidence that individuals frequently exhibit endowment effects does not necessarily imply that corporate law must take this bias into account, however. Evidence that people can exhibit endowment effects does not mean that they invariably do so. Indeed, quite the contrary: the existing evidence suggests that people display endowment effects in some circumstances but not in others. ${ }^{21}$ This heterogeneity raises the question of whether endowment effects exist within the corporate context.

Existing theoretical explanations for the endowment effect do not enable us to predict with confidence when the effect will arise. Economists, psychologists, legal scholars, and others have offered alternative (and often overlapping) explanations for the endowment effect, each of which may have a claim to some veracity. These different theories produce distinct domains

\footnotetext{
${ }^{16}$ This result could not be fully explained by wealth effects, as the mugs did not significantly affect the participants' total wealth, and later variations controlled for any wealth effects of being endowed with the mug without changing the result. Nor was it likely the product of transactions costs, as equivalent mugs were easily available a short distance away at the campus bookstore. Each mug had the price sticker on the bottom. See generally id.

${ }^{17}$ Indeed, a recent ambitious analysis of the existing evidence based on combined data from 45 existing studies found that both experimental tests and empirical studies of real-world choices consistently reveal evidence of an endowment effect. See John K. Horowitz \& Kenneth E. McConnell, A Review of WTA/WTP Studies (Dep't Agric. \& Resource Econ., Univ. Maryland, October 2000).

${ }^{18}$ See, for example, Kahneman, Knetsch, \& Thaler, supra note 6; Daniel Kahneman, Jack L. Knetsch, \& Richard H. Thaler, The Endowment Effect, Loss Aversion and Status Quo Bias, 5 J. Econ. Persp. 193 (1993).

${ }^{19}$ See Jason F. Shogren et al., Resolving Differences in Willingness to Pay and Willingness to Accept, 84 Am. Econ. Rev. 255 (1994) (repeated markets utilizing incentive-compatible bidding systems does not eliminate the endowment effect for nonmarket goods).

${ }^{20}$ In fact, the evidence suggests that the endowment effect manifested by the public generally exceeds that manifested by the college students. See Horowitz \& McConnell, supra note 17.

${ }^{21}$ See generally Arlen, supra note 11, at 1777-78; Jeffrey Rachlinski \& Forest Jourden, Remedies and the Psychology of Ownership, 51 Vand. L. Rev. 1541, 1557 (1998).
} 
for the endowment effect, however, as well as different implications for legal policy.

Indeed, some theorists argue that one can account for the WTA/WTP differential within the conventional rational actor paradigm. ${ }^{22}$ Perhaps the best known of these rational actor explanations posits that the WTA/WTP difference occurs when individuals perceive the good to be partially unique (for example, not to have a perfect consumption substitute) and are unable to easily trade the good through market transactions. This explanation predicts that the effect should not occur if a good has perfect substitutes or if thick markets in the good exist such that individuals can treat the good first and foremost as a simple store of value, rather than as a consumption good with some uniqueness attributes. ${ }^{23}$

If the uniqueness hypothesis were accurate, it would be much easier to predict the endowment effect, because then the phenomenon would co-vary with other objectively verifiable factors, such as the presence of thick markets in a good. Yet existing experimental evidence lends only partial support for the uniqueness conjecture. ${ }^{24}$ In particular, although individuals tend to exhibit no WTA/WTP differential for goods that have only an exchange value (such as money ${ }^{25}$ and exhibit only a modest one for "ordinary market goods,"26 most evidence indicates that the presence of close substitutes merely reduces, but generally does not eliminate, the WTA/WTP differential. ${ }^{27}$ Thus, the

${ }^{22}$ See W. Michael Hanemann, Willingness to Pay and Willingness to Accept, 81 Am. Econ. Rev. 635 (1991); see also Lorne Carmichael \& Bentley Macleod, Caring about Sunk Costs: A Behavioral Solution to the Hold-up Problem (Olin Working Paper No. 99-19, Univ. S. Cal. Law Sch. 2001) (deriving a unique equilibrium that ensures efficiency in holdup models); Gertrud M. Fremling \& Richard A. Posner, Market Signaling of Personal Characteristics (John M. Olin Law \& Econ. Working Paper No. 87, 2d Ser., Univ. Chicago Law Sch. 1999).

${ }^{23}$ Hanemann, supra note 22.

${ }^{24}$ See, for example, Horowitz \& McConnell, supra note 17 (broad literature survey suggests that, on average, the less the good is like an "ordinary market good," the higher is the WTA/ WTP differential).

${ }^{25}$ The best individual evidence for this generalization comes from experiments on "securities"-paper instruments created by experimenters that have no value other than to be redeemed for cash, frequently after some random event determines their value. Broadly construed, such experiments suggest that when comparing securities and cash, WTA and WTP tend strongly to converge. Kahneman, Knetsch, \& Thaler, Endowment Effect, supra note 18; Peter Knez, Vernon L. Smith, \& Arlington W. Williams, Individual Rationality, Market Rationality, and Value Estimation, 75 Am. Econ. Rev. 397 (1985); Harinder Singh, The Disparity between Willingness to Pay and Compensation Demanded: Another Look at Laboratory Evidence, 35 Econ. Letters 263 (1991); Gary H. McClelland \& William D. Schulze, The Disparity between Willingness to Pay versus Willingness to Accept as a Framing Effect, in Frontiers of Mathematical Psychology: Essays in Honor of Clyde Coombs (Donald R. Brown \& J. E. Keith Smith eds. 1991).

${ }^{26}$ See Shogren et al., supra note 19; see also David W. Harless, More Laboratory Evidence on the Disparity between Willingness to Pay and Compensation Demanded, $11 \mathrm{~J}$. Econ. Behav. \& Org. 359 (1989).

${ }^{27}$ See, for example, Wiktor L. Adamowicz, Vinay Bhardwaj, \& Bruce Macnab, Experiments on the Difference between Willingness to Pay and Willingness to Accept, 69 Land Econ. 416, 425 (1993) (finding that WTA/WTP is larger for nonmarket goods than for market goods, but 
endowment effect is, at most, only a partial artifact of nonsubstitutability. ${ }^{28}$

Cognitive psychologists tend to attribute the endowment effect not to traditional rational choice but rather to "loss aversion"-the tendency for people to attach greater importance to losses than to gains. ${ }^{29}$ While descriptively powerful, this psychological explanation does little to predict when the effect will occurs in practice: simply concluding that a person "endowed" with a good exhibits loss aversion adds little to our understanding of which circumstances induce a person to "endow" a good in the first instance. ${ }^{30}$

Indeed, the task of predicting whether people will endow an entitlement is complicated by evidence that endowment does not depend simply on the physical attributes of the object (for example, that it is a university mug) but also on the psychological context of the choice. For example, researchers have found that subjects' psychological sense of "endowment" depends not only on the legal fact of ownership but also on whether subjects feel their status as owners has an independent moral justification. Subjects who were told they had "earned"-or deserved-an object exhibited more of an endowment effect than those who were told they had won the object in a game of chance. ${ }^{31}$ In addition, some evidence suggests that whether an object is

nevertheless finding a WTA/WTP differential for all types of goods). In addition, some scholars cite experimental evidence of a difference between WTA and WTP for lotteries as evidence that the endowment effect operates for market goods. See, for example, Jack Knetsch \& J. A. Sinden, Willingness to Pay and Compensation Demand: Experimental Evidence of an Unexpected Disparity in Measures of Value, 99 Q. J. Econ. 507 (1984) (finding a WTA/WTP differential for lottery/raffle tickets with small stakes). Questions arise, however, whether the lottery valuation results are driven by endowment effects or by biases in the evaluation of uncertain choices, however. See Don L. Coursey, John L. Hovis, \& William D. Schulze, The Disparity between Willingness to Accept and Willingness to Pay Measures of Value, $102 \mathrm{Q}$. J. Econ. 679, 680 (1987).

${ }^{28}$ Additional evidence exists that is inconsistent with rational choice explanations for the endowment effect. For example, subjects who are only given a voucher that can later be exchanged for a mug-and not the actual mug-exhibit a weak endowment effect. See Kahneman, Knetsch, \& Thaler, supra note 6, at 1342 n.7. In addition, the evidence suggests that duration of ownership appears to affect valuation, even when duration does not convey new information about the good. Michael Strahilevitz \& George Loewenstein, The Effects of Ownership History on the Valuation of Objects, 25 J. Consumer Res. 25 (1998).

${ }^{29}$ See Amos Tversky \& Daniel Kahneman, Loss Aversion in Riskless Choice: A ReferenceDependent Model, 106 Q. J. Econ. 1039, 1041-44 (1991). Interestingly, it is possible to incorporate the concept of loss aversion into the conventional utilitarian account of preferences by introducing a "kink" in an individual's indifference curve induced by the status quo. See Gwendolyn C. Morrison, Resolving Differences in Willingness to Pay and Willingness to Accept: Comment, 87 Am. Econ. Rev. 236 (1997); Gwendolyn C. Morrison, Willingness to Pay and Willingness to Accept: Some Evidence of an Endowment Effect, 29 Applied Econ. 411 (1997).

${ }^{30}$ See, for example, Arlen, supra note 11, at 1777-78; Rachlinski \& Jourden, supra note 21 , at 1557; Sunstein, supra note 6, at 1180 . Given the uncertain domain of the endowment effect, and the resulting need for experimental analysis, we need not take any position in this article as to which theory best explains the endowment effect. Each leaves open the question, "under what circumstances do subjects feel endowed?" This experiment is designed to shed additional light on this issue.

${ }^{31}$ See George Loewenstein \& Samuel Issacharoff, Source Dependence in the Valuation of 
viewed primarily for its consumption value or its exchange value can affect the endowment effect-although this can depend as much on the context of the exchange as on the attributes of the asset. For example, a field experiment that tested subjects' willingness to trade sports memorabilia found that while nondealers generally manifested a significant endowment effect, dealers in sports memorabilia did not. Nevertheless, nondealers with substantial trading experience behaved more like dealers than like other nondealers. ${ }^{32}$ Thus, subjects who may endow a particular good in a context where its consumption value is salient may not do so in other contexts, particularly if they have come to focus on its exchange value.

\section{Implications for Agency Relationships}

In spite of the wealth of evidence described above, existing literature leaves unresolved the issue of whether business agents manifest endowment effects in intrafirm exchanges. On the one hand, evidence that subjects manifest endowment effects with respect to university coffee mugs when told they are buyers and sellers suggests the endowment effect may exist in a business context. ${ }^{33}$ On the other hand, the experimental evidence provides two reasons to expect that perhaps agents do not manifest endowment effects in intrafirm exchanges.

First, the evidence that subjects typically fail to manifest the effect for entitlements they hold primarily for exchange purposes raises the possibility that endowment effects will not arise in agency relationships if those entering such relationships view their contractual rights primarily for their exchange value ("exchange-value" hypothesis). ${ }^{34}$

Second, evidence that subjects are less likely to endow an asset to which they do not feel morally "entitled" suggests that agents might not manifest an endowment effect if a sense of loyalty or obligation to the firm mutes their sense of entitlement ("shared-entitlement" hypothesis). ${ }^{35}$ In particular,

Objects, 7 J. Behav. Decision Making 157 (1994) (reporting this result in an experiment with coffee mugs); see also Elizabeth Hoffman \& Matthew Spitzer, Entitlements, Rights and Fairness: An Experimental Examination of Subjects' Concepts of Distributive Justice, $14 \mathrm{~J}$. Legal Stud. 259 (1985) (telling subjects they were entitled to an object affected their willingness to behave selfishly in exercising their property rights in different circumstances); and Elizabeth Hoffman et al., Preferences, Property Rights, and Anonymity in Bargaining Games, 7 Games \& Econ. Behav. 346 (1994) (same).

${ }^{32}$ John List, The Effect of Market Experience on the WTA/WTP Disparity: Evidence from a Field Experiment with Sports Memorabilia (unpublished draft, Univ. Arizona, April 11, 2000).

${ }^{33}$ See Kahneman, Knetsch, \& Thaler, supra note 6, at 1337-38.

${ }^{34}$ The exchange-value hypothesis-that situating subjects in an agency context might mute the endowment effect by causing them to focus on its exchange value-is potentially consistent with evidence that situating subjects in a hypothetical "business" context mutes other-regarding behavior. See Hoffman et al., supra note 31, at 357, table II; K. Binmore, A. Snaked, \& J. Sutton, Testing Noncooperative Bargaining Theory: A Preliminary Study, 75 Am. Econ. Rev. 1178 (1985).

${ }^{35}$ See Loewenstein \& Issacharoff, supra note 31. 
agents might not endow if entering into an agency relationship causes them to feel that the firm is entitled to the assets implicated in the relationship, resulting in a sense of shared or incomplete entitlement. ${ }^{36}$ This would be particularly likely to mute the endowment effect when an agent's decision whether to keep the asset affects the firm's welfare.

To assess these possibilities, we conducted an experimental test with subjects situated in an agency context. We now turn to this analysis.

\section{THE EXPERIMENT}

To examine whether business agency relationships alter the endowment effect, we conducted a series of experiments to test the robustness of the effect by situating subjects in an employment relationship involving intrafirm exchanges. In each set of experiments, subjects were differentiated by whether they were endowed with an asset at the beginning of the experiment. The initial "control" experiment replicated prior work on the endowment effect. As expected, subjects participating in this experiment exhibited significant endowment effects. We then conducted a pair of "agency" experiments in which subjects were told they were to be employed by a for-profit firm and would face a choice between keeping/obtaining the tangible good or receiving a higher monetary wage. They also were told that the good was a potential factor of production for the firm and that the firm's profits would be higher if it used the good. After choosing whether to join the firm, those who did then determined whether to keep/obtain the asset or a prespecified higher monetary wage (with endowed subjects deciding whether to give up the asset and unendowed subjects deciding whether to take the firm's asset). We determined the subjects' WTA or WTP by eliciting their willingness to exchange the mug for money (the higher wage offered varied), conditioned on whether they were initially endowed. Our central finding is that, in contrast with our control subjects, our agency subjects did not manifest a statistically significant endowment effect. This finding is suggestive of a significant interaction between endowment effects and the principal-agent context that operates to mute-and perhaps eliminate-the endowment effect. This section describes these experiments and presents our results.

\section{A. Experimental Procedures}

The experiment involved a total of 180 subjects: 35 participated in a control experiment that established the endowment effect in a traditional setting, and the remaining 145 subjects participated in a series of experiments designed to explicitly test for endowment effects in agency relationships. All subjects

\footnotetext{
${ }^{36}$ This would be particularly likely to the extent that agents manifest other-regarding preferences toward their principal, as fiduciary-duty law asserts they should (but economic principalagent models generally assume they do not).
} 
were first-year students at the University of Southern California (USC) Law School who participated either in the 3 weeks before entering law school or in the first few weeks of their first semester of law school. ${ }^{37}$ The subjects were essentially equally divided between men and women, with 94 women in our total pool of 180 . All subjects were assigned a subject identification (ID) and were truthfully informed that all data were to be recorded only by subject ID number, thereby preserving anonymity. ${ }^{38}$

As in the classic endowment effect experiments, our subjects were randomly divided between those who were endowed with a university (USC) coffee mug at the beginning of the experiment and those who were not. Consistent with the literature, the identical mugs were purchased from the nearby campus bookstore, sported a familiar school logo, and were clearly labeled as being available at the bookstore for $\$ 5.95 . .^{39}$ We selected university mugs over other possible tangible assets because prior work had already established a relatively reliable baseline for such objects. Thus mugs were particularly suited to testing the robustness of prior results to situating subjects in a business agency relationship. ${ }^{40}$

To ensure that all subjects understood the experimental design, each received a written description of the experiment at the outset (see the Appendix). We also read this description aloud. In addition, in the agency experiments, each subject participated in two practice rounds of the experiment following the description and then answered a series of questions that tested whether the subject understood the experimental design. (At the beginning of the experiment, we told subjects that they would not be permitted to complete the experiment if they could not answer the test questions adequately.) $)^{41}$

\footnotetext{
${ }^{37}$ The final experiments were run in fall 2000 . We also collected data on a different, earlier, version of the experiment run between March and May 1999, with over 100 second- and thirdyear students comprising the subject pool. The results of that prior experiment are largely consistent with those we report here.

${ }^{38}$ Throughout the main part of the experiment (when subjects were deciding on whether to exchange the mug), the experimenters stayed in the front of the room, where we could monitor the progress of the experiment but could not see the subjects' answers to specific questions.

${ }^{39}$ Easy availability is important to ensure that we are testing endowment effects, as opposed to the transactions costs to an endowed subject of obtaining another mug should she sell one in this experiment.

${ }^{40}$ We employed a mug because previous literature has shown the endowment effect is sensitive to the type of asset used. Thus, to help ensure that any results we obtain were the product of a change in context-as opposed to a change in the type of asset-we employed the same asset as previous experiments. Needless to say, had we found an endowment effect, we would then have needed run additional experiments with assets that more closely approximate those involved in business agency relationships before we could conclude that the endowment effect affects agents' exchanges with their employers. While such a research agenda is worthwhile, we concluded that at this point the more pressing policy issue is to determine the degree to which experimental results are robust to being situated in the agency context.

${ }^{41}$ Prior to beginning the formal experiment, each subject also answered a series of demographic questions-including age, gender, race, marital status (single, married, or cohabiting),
} 
In all experiments, each endowed subject received a mug at the very beginning of the experiment, prior to the consent form being read. The mug rested in front of the subject for the approximately 30 minutes of explanation and testing prior to the subjects' participating in the main part of the experiment and remained with the subjects during the experiment. Previous experiments have shown this is more than long enough to produce an endowment effect. ${ }^{42}$ The unendowed subjects were allowed to examine a mug at the beginning of the experiment but were not endowed with it. ${ }^{43}$

Each subject received $\$ 5$ simply to participate in the experiment. The "control-group" subjects were told that if they completed the experiment, they would receive additional remuneration, ranging from $\$ 1$ to $\$ 9$ in cash or, potentially, a mug, depending on the choices they made during the experiment. The agency subjects were told they faced potential additional remuneration of $\$ 2-\$ 15$ and/or, potentially, a mug, depending on the choices they made during the experiment. Prior experimental literature indicates that these payoff levels are sufficient to induce subjects to care about the choices they make. ${ }^{44}$

\section{B. The Control Group}

The 35 control-group subjects participated in an experiment designed to replicate the basic endowment effect experiments, in order to ensure that our subjects would indeed manifest an endowment effect with respect to a USC coffee mug outside of the agency context. These control subjects were divided into two groups: "endowed" $(n=18)$ and "unendowed" $(n=17) .{ }^{45}$ The

number of siblings, whether English was the subject's native language, undergraduate major, and a question designed to measure their attitude toward risk. This information was on a sheet of paper identified only with the subject's ID. We coded for gender because it has been shown to infuence endowment effects in other settings. See, for example, Michael Strahilevitz \& George Loewenstein, Gender Differences in the Effect of Duration of Ownership on Object Valuation (Working paper, Dep't Soc. \& Decision Sciences, Carnegie Mellon Univ. 2000). We coded other demographic variables because research has shown that variables such as undergraduate major affect various biases. See, for example, Robert H. Frank, Dennis T. Regan, \& Tom Gilovich, Does Studying Economics Inhibit Cooperation? 7 J. Econ. Persp. 159, 160-12 (1993); Robert Frank, Dennis Regan, \& Tom Gilovich, Do Economists Make Bad Citizens? 10 J. Econ. Persp. 187 (1996).

${ }^{42}$ Evidence suggests that subjects endow objects quite quickly-after possessing them for a very short period of time (for example, 5 minutes). For women, the endowment effect appears to increase with duration of ownership. Strahilevitz \& Loewenstein, supra note 41.

${ }^{43}$ Each subject participated in only one version of the experiment (we did not allow any subject to participate in the endowed version and then later in the unendowed version). This is important because evidence suggests that past ownership of an object-for example, in a prior endowed experiment-affects unendowed subjects' behavior. See Strahilevitz \& Lowenstein, supra note 28.

${ }^{44}$ See Colin F. Camerer \& Robin M. Hogarth, The Effects of Financial Incentives in Experiments: A Review and Capital-Labor-Production Framework, 19 J. Risk \& Uncertainty 7 (1999).

${ }^{45}$ The subjects were not told the name of the groups that they were placed in. 
endowed subjects were given a mug at the beginning of the experiment; the unendowed were not. Each subject was asked a series of questions about her preferences between the mug and a stipulated monetary amount, with the stipulated prices ranging from $\$ 1$ to $\$ 9$, in $\$ .50$ increments. ${ }^{46}$

The subjects were told that at the end of the experiment, a monetary amount would be selected randomly, ${ }^{47}$ and each subject's revealed preference at that amount would be effected. Thus, if at the end of the experiment the amount $\$ 5.50$ was selected randomly, then each subject would receive either $\$ 5.50$ or a mug depending on whether she had indicated a preference for the mug or $\$ 5.50$ on the choice sheet.

As in previous experiments, we tested for the endowment effect by comparing the price at which our endowed subjects were willing to exchange the mug for money with the price at which our unendowed subjects opted for money instead of the mug: in other words, we compared the WTA of our endowed subjects with the WTP of our unendowed subjects.

Consistent with prior evidence, our control group manifested a pronounced endowment effect. As shown in Figure 1, the rate at which subjects preferred money over the mug is consistently greater for unendowed subjects than for endowed subjects at virtually every price. For example, in order to induce 50 percent of the subjects to select money instead of the mug, it would be necessary to offer endowed subjects approximately $\$ 5$, whereas a payment of only just over $\$ 2$ was sufficient to induce 50 percent of the unendowed subjects to pass up the mug - thus, the endowed subjects required a premium of approximately $\$ 3$ to induce a 50 percent contribution rate. Moreover, at the modest $\$ 2$ price at which approximately half the unendowed subjects chose cash, more than 90 percent of the endowed subjects opted to keep the

\footnotetext{
${ }^{46}$ Specifically, the endowed subjects in the control group were given the following instructions:
}

You now have, and own, a mug which you can keep and take home. You also have the option of selling it and receiving money for it. For each of the possible prices listed below, please indicate whether you wish to (1) receive that amount of money and sell your mug or (2) keep your mug and not sell it as this price. These instructions will look as follows. For each price you will indicate your decision by marking an $\mathrm{X}$ in the appropriate column.

If the price is $\$ 1$

I will keep the mug

I will sell

If the price is $\$ 1.50$

If the price is $\$ 9$

The unendowed subjects received similar instructions, although these asked them to "choose" between a money and mug that they did not yet own (as opposed to assessing sale prices). These instructions are based on Kahneman, Knetsch, \& Thaler, supra note 16. We used this specification rather than the instructions from the original endowment effect experiment because of the possibility of strategic behavior inherent in the original formulation.

${ }^{47}$ Specifically, subjects were told that slips of paper that represented each listed monetary amount would be put into a hat and a subject would draw an amount from the hat. 


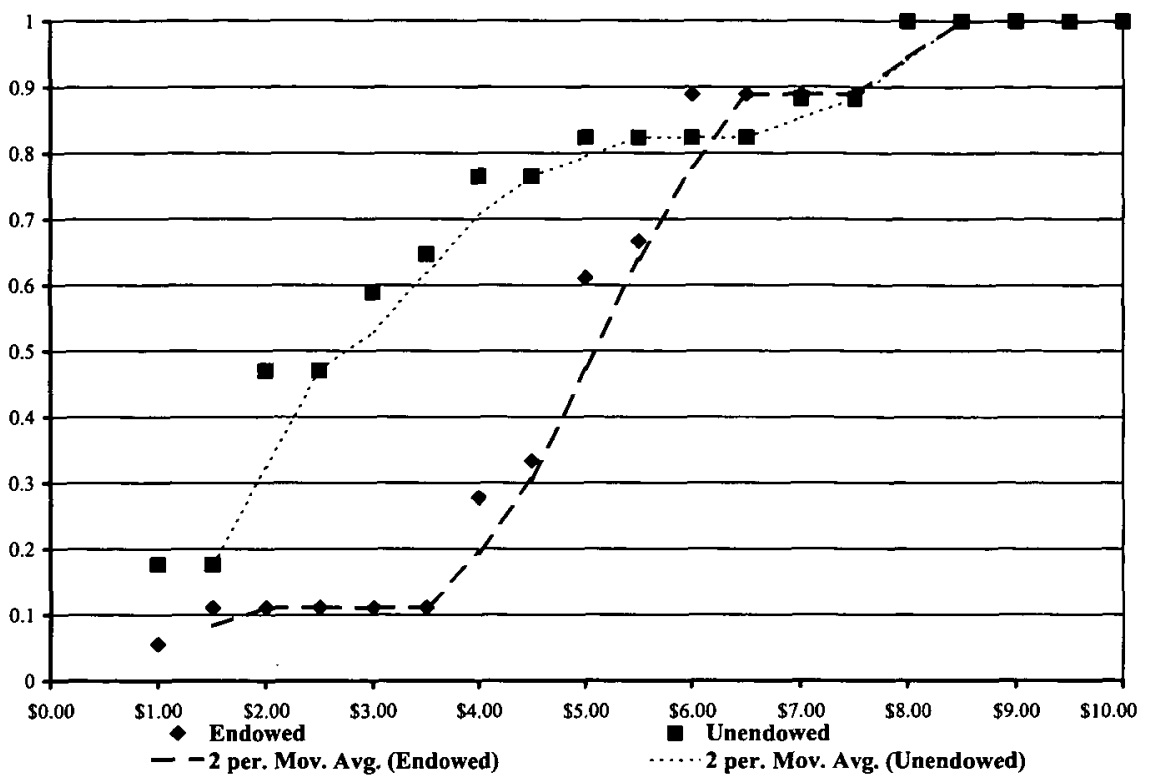

FIGURE 1.-Rate at which control group opted for money over mug

mug over the money. Overall, the median WTA of endowed subjects $(\$ 4.50)$ exceeded the median WTP of unendowed subjects $(\$ 2.50)$ by fully $\$ 2.00$.

The clear graphical distinction between the subjects' WTA and WTP is also reflected in statistical tests. The mean WTA of the endowed subjects $(\$ 4.71)$ exceeded the mean WTP of the unendowed subjects $(\$ 3.14)$ by a full $\$ 1.57-\mathrm{a}$ figure that is also statistically significant (one-sided $t$-test, $p=.0175, \mathrm{df}=33$ ). Likewise, a nonparametric two-sample Wilcoxon ranksum test also rejects the null hypothesis of distributional symmetry $(z=$ $2.328, p=.0199$ ). These differences are comparable in both their strength and numerical magnitude to the existing literature and are consistent with the conclusion that USC Law School students appear to be comparable to other subject groups.

\section{Initial Agency Experiment}

Having established that our subject population displays endowment effects in the standard experimental context, we next examined whether these effects persist when subjects are placed in a business agency relationship. Our initial hypothesis was that corporate agency relationships could mute the endowment effect for one of two reasons. First, agents of corporations might not display such effects if transacting with the firm causes them to focus on their entitlements as units of exchange rather than objects with consumption value 
(the "exchange value" hypothesis). ${ }^{48}$ Second, agents' sense of loyalty to their corporate employers might cause them to feel that the firm also is somehow "entitled" to assets they own that might benefit the firm, thus muting the endowment effect by causing endowed subjects to "pool" their entitlements with those of the firm (the "shared-entitlement" hypothesis). To test whether either or both of these effects in business agency relationships dampened the endowment effect, we altered the experiment to introduce an employment relationship. We describe the specifics of this experiment below.

\section{Detailed Description of the Experiment}

The agency cost experiment involved 69 subjects: 29 "endowed" subjects (who received a mug at the beginning of the experiment) and 40 "unendowed" subjects. In this experiment, subjects were informed that they were being offered a managerial job by a for-profit corporation, Amalgamated Products, and that the mug was a potential factor of production for the firm. ${ }^{49}$ In each round of the experiment, subjects received a contractual offer to work as a manager for the firm. The contract was contingent on the firm's performance, however, and would pay a different amount of money depending on whether the firm earned a low profit or a high profit. The amount offered if the firm earned a low profit was always $\$ 2$, but the amount offered if the firm earned a high profit (the "high wage") varied from $\$ 3$ to $\$ 15$.

Subjects were told that whether the firm earned low or high profits depended entirely on whether the firm used a mug as a factor of production. Each endowed subject was told that the firm could use a mug only if the subject parted with her own. Each unendowed subject was told she would be given control of the firm's mug and could either leave the mug with the firm or take for it for herself. Each subject was informed that if the firm did not use the mug, profits would be low, and the subject would get a wage of only $\$ 2$. By contrast, should the firm be allowed to use the mug, profits would be high, and the subject would earn the higher wage specified in the contract during that round.

Thus in each round the subjects faced two choices. The first decision was whether to agree to work for the firm. ${ }^{50}$ Any subject who refused the contract

\footnotetext{
${ }^{48}$ This might be particularly true to the extent that agents expect to use their assets as a factor of production.

${ }^{49}$ To gain insight into the robustness of prior experimental results to the agency context, we purposefully situated our subjects in a very "thin" agency relationship-a fictitious firm that made unilateral offers on preprinted pages (with no human representative). Evidence that such a weak relationship altered experimental results would suggest that these results are not robust to the agency context and would provide strong evidence that endowment effects would be altered by the stronger agency relationships prevalent in the "real world."

${ }^{50}$ We selected a two-stage decision process because we were interested in whether the act of first committing to work for a firm-knowing the firm needed the mug as a factor of production-might depress the endowed subjects' sense of entitlement, thereby reducing or eliminating the endowment effect.
} 
would earn nothing for that round. (The endowed subjects could keep the mug; the unendowed obviously could not.) All subjects who agreed to work for the firm then faced a second choice: whether to allow the firm to use the mug as a factor of production in return for a higher salary or whether to keep/obtain the mug for themselves. For the endowed subjects, this effectively involved a decision of whether to sell the mug to the firm for a specified higher wage. For the unendowed subjects, this involved a decision of whether to claim the mug from the firm in return for a specified lower wage.

Each subject participated in eight rounds of the experiment. Subjects were told that their actual compensation from the experiment would include their earnings from one of the eight rounds, selected at random at the end of the experiment. ${ }^{51}$ We emphasized to the students that their choices in one round would not affect their options in other rounds. To make this promise credible, each subject received all the questions they would be asked in advance, so that they would feel confident that their initial choices would not affect the other bids they would be offered..$^{52}$ Moreover, in order to avoid one subject's choices influencing others', the subjects were seated apart from each other. The high-wage offers in each packet were also presented in a different order to each subject, so that in any given round no two subjects seated near each other had the same offer. Upon completion of the final round, we used an eight-sided die to choose the round that would determine the subjects' actual payoffs. The subjects then accepted payment in cash. Any endowed subject who had chosen to contribute the mug to the firm in the selected round also handed her mug back to the experimenter.

This design allows us to impute each subject's approximate valuation of the mug at the end of the eight rounds. First, note that for either group, a strategy of accepting the contract and keeping the mug strictly dominates rejecting the contract. By rejecting the contract, the subject gets either the mug (if endowed) or nothing (if unendowed), but by accepting the contract and then keeping the mug, the subject can guarantee herself the mug plus $\$ 2$. Thus, we predicted-correctly - that virtually all subjects who understood the experiment would accept the contract in every round. ${ }^{53}$ The principal choice of interest for those accepting the contract, then, is whether to choose

\footnotetext{
${ }^{{ }^{1} 1}$ Each subject also received $\$ 5$ for simply participating in the experiment.

${ }^{52}$ In addition, in order to ensure that students' answers were not affected by future questions, we told students they must all proceed at the same pace, could not turn a page unless told, and then carefully monitored whether they did so (given the setup in the rooms, this was easily done). Moreover, we accurately informed students that although each student was given the same set of contracts, the order in which the contracts were presented to the students varied across students, to ensure that students would not adjust their answers based on those given by their neighbors. Also, the "high-wage" contracts were not done sequentially: a subject might well receive a $\$ 3$ "high-wage" offer, followed by a $\$ 15$ one, and then a $\$ 4$ one.

${ }^{53}$ Interestingly, very few subjects rejected the contract in one or more rounds. Although these subjects are excluded from the current article (on the basis of assumed inconsistency), one might be able to tell a convincing story for leaving them in.
} 
the package outcome of (low wage, mug\} or the alternative allocation of \{high wage, no mug\}. By varying the high-wage offers by round, we were determining the critical wage $w_{\mathrm{h}}$ that would just induce subjects in each condition to choose the nonmug allocation, thereby allowing the firm to use the mug in production. Subtracting the $\$ 2$ baseline wage from this amount yields an estimate of the subject's implicit valuation.

Evidence that the endowed subjects required a greater payoff to part with the mug than the unendowed subjects would require to abstain from claiming it would constitute evidence of endowment effects in this context. ${ }^{54} \mathrm{~A}$ lack of significant difference between the respective wage offers required to induce the two groups to part with (not take) the mug would thereby constitute evidence that the agency context interacts importantly with the endowment effect, with the context significantly dampening its magnitude.

\section{The Results}

In contrast with our control group, our agency subjects did not display a significant endowment effect.

Consider Figure 2, which presents the relative frequency with which the endowed and unendowed subjects passed up possession of the mug, conditional on the high-wage offer. The horizontal axis of Figure 2 depicts the difference between the wage offered to the subjects in the "high-payoff" and the "low-payoff" states of the world. The vertical axis depicts the empirical frequency with which subjects chose the allocation that left them without a mug. ${ }^{55}$ As before, the figure also illustrates the trends in each cell through the use of a 2-period moving average.

Examination of Figure 2 suggests that the agency context substantially mutes the endowment effect. In contrast with the control experiment-in which the endowed subjects valued the mug on average $\$ 1.57$ more than the unendowed subjects-the difference in relative valuations evidenced by our endowed and unendowed agency subjects are nowhere near that level and, indeed, do not appear to be of particular economic significance. Indeed, the two samples display an identical median valuation of $\$ 3.00$. On first blush, then, this figure provides preliminary evidence that our subjects did not

\footnotetext{
${ }^{54}$ Such a finding would only have been consistent with such a result, because there would have been other possible explanations-for example, that subjects felt guilty about "taking" the firm's mug, with guilt resulting in unendowed subjects placing a particularly low value on the mug. Since guilt would only exacerbate a valuation differences between our endowed and unendowed subjects, we need not control for it given our result of no significant differences in the behavior of the two groups.

${ }^{55}$ Thus, for the endowed condition, the vertical axis depicts the frequency with which subjects "contributed" their mug; for the unendowed condition, it depicts the frequency with which subjects "abstained from taking" the firm's mug; and for the exchange-value condition, it depicts the frequency with which subjects chose the no-mug/high-payoff contract.
} 


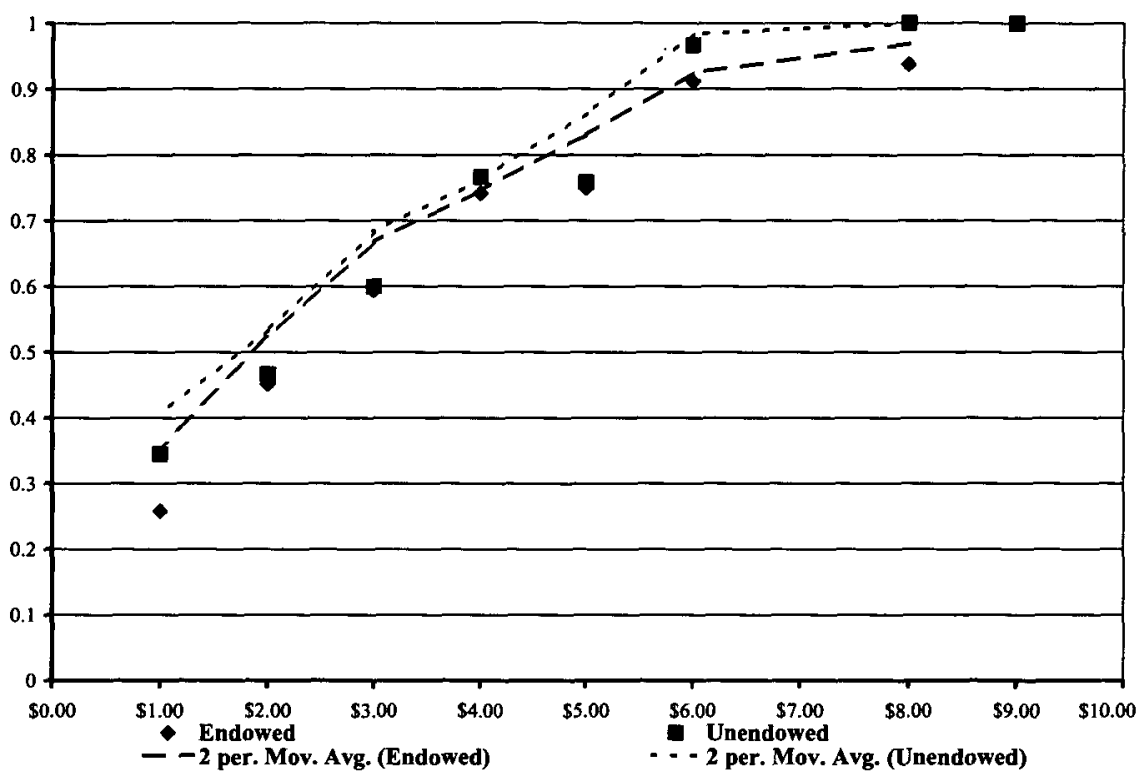

FIGURE 2.-Rate at which agency condition subjects opted for money over mug. The horizontal axis denotes $w_{\mathrm{h}}-w_{\mathrm{l}}$.

manifest an economically significant endowment effect-and certainly nowhere near the effect found in previous experiments (if at all).

Analysis of other summary statistics corroborates this conclusion. The slight numerical differences between WTA and WTP in our agency condition subjects are not statistically different from zero. Specifically, the endowed subjects had a mean WTA of $\$ 3.08$, whereas the unendowed subjects had a mean WTP of $\$ 2.95$, a difference of $\$ .13$ that is not statistically significant at any conventional level (two-tailed $t$-test, $p=.806, \mathrm{df}=67$ ). Likewise, a nonparametric two-sample Wilcoxon rank-sum test fails to reject the null hypothesis of distributional symmetry $(z=.025, p=.9803) .^{56}$

Although these summary statistics are relatively powerful themselves, we employed regression analysis to confirm that the dampening effect observed in our agency analysis was not the result of some other observed demographic trait. Our primary question is whether the endowed and unendowed subjects exhibit significant cross-group difference, when we control for wage (and

\footnotetext{
${ }^{56}$ On inspection of Figure 2, one can also make some conclusions about whether our results are numerically (as opposed to statistically) significant. Indeed, one stark aspect about the figure is how close each of the depicted schedules are to one another. This certainly does not suggest the manyfold WTA/WTP ratios found in previous endowment effect experiments. See Section IIA supra.
} 
TABLE 1

Random-EFFects Logit on Agency-Condition SubJects

\begin{tabular}{lccc}
\hline & $(1)$ & $(2)$ & $(3)$ \\
\hline$w_{\mathrm{h}}$ & 1.058897 & 1.033449 & 1.034438 \\
& $(.1286107)^{*}$ & $(.122762)^{*}$ & $(.1230016)^{*}$ \\
Unendowed & .3510971 & .3579227 & \\
& $(.7365878)$ & $(.8592371)$ & \\
ManySibs ( $\geq 2)$ & -1.888621 & & \\
& $(.7710764)^{*}$ & & \\
Female & .5573271 & & \\
& $(.7432729)$ & & \\
Married/cohabitating & 1.392177 & & \\
& $(.8834465)^{+}$ & & \\
Nonwhite & .4721307 & & \\
& $(.8822647)$ & & \\
Social science major & -1.757632 & & \\
& $(.8089902)^{*}$ & & \\
Log likelihood & -163.31138 & -170.56895 & \\
\hline
\end{tabular}

Note. - Baseline case: endowed condition. The constant term is not reported. Standard errors are in parentheses.

+ Significant at the $90 \%$ level.

* Significant at the $95 \%$ level.

possibly other factors). In order to make full use of our data structure, we first estimated the following basic relation:

$$
\operatorname{Pr}\left\{\operatorname{NoMug}_{i j}=1\right\}=\operatorname{Pr}\left\{\gamma^{\prime} X_{i j}+\varepsilon_{i j}>0\right\},
$$

where the left-hand side denotes the probability that a randomly selected subject (subject $i$ ) in a randomly selected round (round $j$ ) will choose to part with the mug ( $\operatorname{NoMug}_{i j}=1$ ), and the right-hand side denotes the probability that a linear combination of independent variables for that subject/round $\left(X_{i j}\right)$ that represents subject characteristics (for example, wage offers, subject treatment dummy variables, and demographic characteristics) with a set of coefficients $(\gamma)$, summed with an error term $\left(\varepsilon_{i j}\right)$, exceeds zero, and in which $\varepsilon_{i j}$ has a specified distribution. The panel structure of our data set necessitates that we control for individual-subject effects through the rounds. Therefore, we report the results from a random-effects logit approach ${ }^{57}$ in Table 1, with the endowed condition as the baseline. For the purposes of controlling for

${ }^{57}$ In performing these estimations, it is important to keep two factors in mind. First, the dependent variable of interest $\left(\mathrm{NoMug}_{i j}\right)$ is qualitative in nature, and thus ordinary least squares regression is inappropriate. Second, our data set is a panel data set, involving both crosssectional and time-series dimensions (that is, numerous subjects, each of whom plays multiple rounds). As such, error terms in the above estimation $\left(\varepsilon_{i j}\right)$ are likely to be highly correlated across subjects. See, for example, M. R. Conway, A Random Effects Model for Binary Data, 46 Biometrics 317 (1990). As a robustness check, we have done the same set of estimations using fixed effect approaches and a linear probability (generalized least squares) approach. Those results are not reproduced here but are qualitatively similar. 
error variance, we also included other demographic variables ${ }^{58}$ in specification (1) (although we obviously are not attempting to test a positive theory about the relationship between demographic variables on manifest endowment effects).

As shown in specification (2) of Table 1, membership in the unendowed condition has no numerically or statistically significant effect on the likelihood of parting with the mug. This statistical insignificance appears to hold for any number of alternative specifications of the estimated model and does not seem to turn on the inclusion of other demographic regressors (reported in specification (1)) or various interaction terms (not reported).

The observation that imputed values converge in the agency context, while important in its own right, raises the question of why this convergence occurs. In particular, it leaves open questions of whether introducing the agency context (1) dampens the initial ownership valuation of an endowed subject, (2) strengthens the initial valuation of an unendowed subject, or (3) has both effects simultaneously. We now turn to this question.

Table 2 reports the results of a series of ordinary least squares regressions in which the dependent variable is the subject's imputed valuation of the mug. As noted above, for the subjects in the control conditions, this value was elicited directly; for the subjects in the agency conditions, we computed this valuation (as noted above) by taking the difference between the high and low wages offered at the smallest value of $w_{h}$ at which the subject opted for the higher wage rather than the mug. Perhaps the most telling specification is (2), which regresses subjects' imputed valuations on three dummy variables that correspond to our differing treatments, with the unendowed control group serving as a baseline. Note from the table that membership in either the endowed or unendowed agent group does not have a significant effect on predicted valuation. In other words, subjects in these groups appear to be behaving similarly to those in the baseline group of unendowed control subjects. Indeed, testing the hypothesis that these coefficients are jointly zero is consistent with this conjecture $(F(2,100)=.05 ; p=.95)$. Indeed, the only subgroup that appears to act in a significantly different fashion is the control-group subjects who were endowed with a mug: it is these subjects who value the mug more, thus generating a significant endowment effect. By contrast, putting an endowed individual into an agency relationship apparently induces her to behave as if she was never endowed to begin with. This pattern is consistent in the other two specifications ((1) and (3)), which

\footnotetext{
${ }^{58}$ In particular, we included demographic characteristics such as a sex dummy, a dummy for whether the subject had two or more siblings in his/her household growing up, the marital/ domestic partner status of the subject, whether the subject was nonwhite, and whether the subject was a social science major as an undergraduate. We included such demographics as a robustness check, given the existence of some research indicating that certain demographic traits (such as sex) are predictive of manifest biases. See sources cited in note 41 supra.
} 
TABLE 2

Ordinary least Squares Regression: Agency and Control Subjects

\begin{tabular}{lccc}
\hline & $(1)$ & $(2)$ & $(3)$ \\
\hline Endowed control & 1.653881 & 1.561275 & 1.652405 \\
Endowed agent & $(.7432859)^{*}$ & $(.7593732)^{*}$ & $(.7406837)^{*}$ \\
& .2292936 & -.198783 & \\
Unendowed agent & $(.6858855)$ & $(.685863)$ & \\
& .5380047 & -.0595588 & \\
Endowed or unendowed agent & $(.6709513)$ & $(.6500772)$ & \\
& & & .394256 \\
Age & & & $(.61931)$ \\
& -.0529787 & & -.0542684 \\
Female & $(.0412152)$ & & $(.0410088)$ \\
& -.9531691 & & -.9296653 \\
Nonwhite & $(.439881)^{*}$ & & $(.4364033)^{*}$ \\
& -.4849271 & & -.4476269 \\
Social science major & $(.465969)$ & & $(.4597143)$ \\
& .5549345 & .5344027 \\
Constant & $(.4796419)$ & & $(.4766088)$ \\
& 4.448292 & 3.147059 & 3.147059 \\
$F$ & $(1.262905)$ & $(.5445747)^{*}$ & $(.5445747)^{*}$ \\
Adjusted $R^{2}$ & $2.58 *$ & $.73^{*}$ & $2.98^{*}$ \\
& .0972 & .0758 & .1035 \\
\hline
\end{tabular}

Nore. -Dependent variable: subject's implied valuation. Baseline: unendowed control group. Standard errors are in parentheses.

* Significant at the $5 \%$ level.

add additional demographic variables and combines the agency subjects into a single categorical dummy.

Another way to see this effect graphically is to overlay Figures 1 and 2, as represented in Figure 3 (in dollar increments). ${ }^{59}$ What is immediately striking about the figure is the extent to which the chooser group overlaps with both agency conditions, with the seller group alone manifesting a significantly smaller willingness to part with the mug at every price except the highest (indicating a greater implicit valuation of the mug). Once again, the figure is highly suggestive of a dampening effect for endowed subjects when placed within an agency context.

\section{Quality of the Results}

Although the interaction effect between agency contexts and manifest endowment effects appears to be strong, we nonetheless considered whether certain limitations of our experimental design hampered the reliability of our statistical analysis. Below we discuss four of the most pertinent limitations. Experiment Complexity and Insignificant Stakes. We first considered the

${ }^{59}$ Because the agency group subjects had their valuations elicited in dollar increments only, Figure 3 superimposes only the integer dollar observations of the control group (from Figure 1). on the agency group (from Figure 2). 


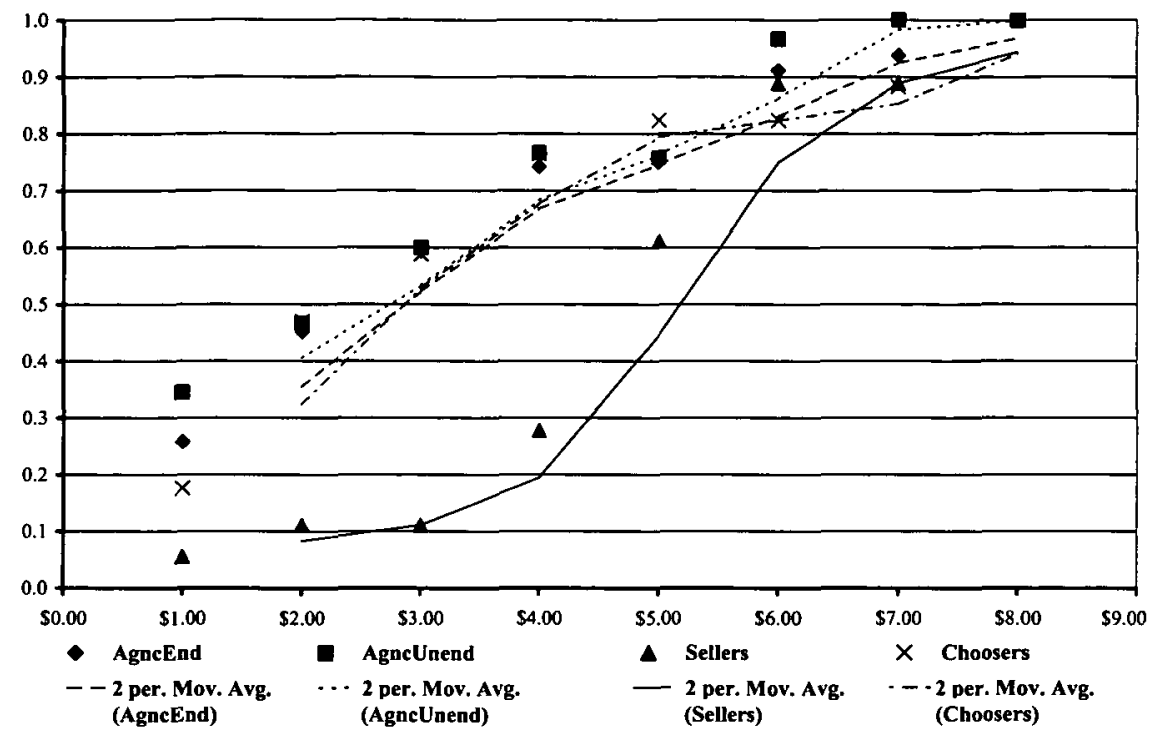

FIGURE 3.-Comparing control subject to agency subjects

possibility that the experiment was too complex for subjects to understand and/or that monetary stakes involved in the experiment were too low to induce the subjects to attend seriously to the decision before them. We rejected these alternative explanations for several reasons.

First, previous experimental literature suggests that our payoff levels are sufficient to induce subjects to care about the choices they make. ${ }^{60}$ Second, payoff levels in the agency condition were within the range of the payoffs employed in the control experiment, in which subjects did manifest an endowment effect. Third, the subjects' behavior suggests that the stakes were sufficient to generate differentiation between groups. Both endowed and unendowed subjects were responsive to financial incentives: as the "price" for the mug (that is, the wage difference, $w_{\mathrm{h}}-w_{1}$ ) increased, subjects increasingly selected the all-cash allocation instead of keeping the mug. Indeed, at the low end of the scale $\left(w_{\mathrm{h}}=\$ 3\right)$, no group of subjects passed up the mug at a rate of more than 35 percent, whereas at the high rate of the scale $\left(w_{\mathrm{h}}=\$ 11\right)$, subjects in all groups parted with the mug at a greater than 95 percent rate. Moreover, Figure 2 reveals that the frequency with which subjects part with the mug is monotonically increasing in the high wage, $w_{\mathrm{h}}{ }^{61}$ This is a strong indication that the monetary amounts at stake are both

${ }^{60}$ See Camerer \& Hogarth, supra note 44.

${ }^{61}$ The one weak exception occurs with unendowed subjects, who part with the mug at a constant 75 percent rate for both $w_{\mathrm{h}}=\$ 6$ and $w_{\mathrm{h}}=\$ 7$. 
sufficiently large and variable to obtain meaningful results. Indeed, if the monetary stakes were so small as to be considered trivial by subjects, we would expect to observe seemingly random behavior in all conditions. Finally, consistent with well-behaved results, we note that the unendowed subjects in the agency experiment were everywhere more willing to give up the mug than the endowed subjects (in other words, the two lines do not cross)—although the difference is neither economically nor statistically significant. ${ }^{62}$

Differences in the Subject Populations. We also considered the possibility that differences in the subject pools in the two groups-endowed and unendowed-might be driving our results. We believe this is unlikely. The subjects were randomly distributed between the two groups, and we therefore have no systematic reason to expect that the two subject pools are different.

We nevertheless did consider the possibility that demographic differences in the population might be masking the endowment effect. In particular, there is some evidence that women value objects differently than men. ${ }^{63}$ Thus we considered whether gender differences might be affecting our findings as well. Gender differences in the subject populations could mask an endowment effect if women valued the mug less than men, and if women comprised a greater proportion of the endowed subjects than of the unendowed subjects.

Our data confirm the importance of considering the role of gender differences, revealing that women and men subjects did tend to value the mugs differently in both experiments. For instance, in Table 1, women were more likely, all else held constant, to part with the mug at every wage level. Similarly, in Table 2, the implicit value placed on the mug by women subjects was approximately $\$ .90$ lower than that of men.

Nevertheless, we did not find any evidence that these gender differences account for our finding that the agency context mutes the endowment effect. Gender differences would plausibly mute evidence of an endowment effect only if a disproportionate number of the endowed subjects were women in the agency experiment. In our agency experiment, 57 percent of the total group were women, while the endowed subgroup consisted of 52 percent women (very close to our representative total). Moreover, in both specifications (1) and (3) above (and in Table 1), our principal results attempt to control for gender, and our interaction result is robust to that finding. Finally, if gender biases were muting significant endowment effects in the agent

\footnotetext{
${ }^{62}$ Our conclusion that the subjects understood the experiment is supported by our interactions with the subjects, which indicated they were not confused. After reading the consent form, we gave the subjects an opportunity to ask questions. Subjects then played two practice rounds, to help ensure that they understood the experiment. Following the practice rounds, the subjects answered a detailed questionnaire designed to ensure that they understood the experiment. Finally, the choice the subjects had to make was quite straightforward: have a mug or get more money.

${ }^{63}$ See Strahilevitz \& Loewenstein, supra note 41.
} 
condition, we would expect to find evidence of an endowment effect in a single-gender subgroup. Testing for endowment effects in the male-only and female-only subpopulations of the agent condition reveals no significant evidence of an endowment effect. ${ }^{64}$

Condition Mismatch. We also considered the possibility that our results from the control and agency conditions are simply not comparable. While the predominant distinction between these two groups is one of framing and context (that is, the exact effect we wish to test), it is important to acknowledge that the two sets of data were gathered using slightly different protocols. In particular, the control-group valuations were elicited simultaneously in a single round, while the agency group valuations were collected ad seriatim in randomized rounds of simulated bargaining. Moreover, the minimal increments for valuation tested were smaller (at \$.50) for the control-group than they were for the agency group (at $\$ 1.00$ ). Finally, subjects in the agency group were always guaranteed a payment of $\$ 2$ more than those in the control group would receive, possibly giving rise to income effects. Given our data structure, then, one might conceivably argue that any cross-condition differences we find are an artifact of some of these other asymmetries.

We believe, however, that such concerns are assuaged by a few important considerations. First, our agency condition generates implicit valuations that square almost precisely with those in the unendowed control group. Indeed, as noted above, there is no statistical difference between the responses in these three constituent groups. As such, we feel relatively confident that even despite the slight differences in experimental protocol, the two groups are statistically comparable. Second, to our knowledge, the existing literature provides little indication that sequential elicitation of valuations works to eliminate the endowment effect entirely. While some studies have found that learning reduces the phenomenon over time, ${ }^{65}$ the subjects within our agency conditions exhibit virtually no endowment effect at all on average.

Nevertheless, it is possible to gain at least some purchase on whether such learning considerations carry significant weight by concentrating our analysis on the initial rounds of the agency experiment. If a learning effect is substantially at play, we would expect a larger difference between the behavior of endowed and unendowed subjects early on in that experiment (both numerically and statistically), with convergence occurring only later. ${ }^{66}$ To ex-

\footnotetext{
${ }^{64}$ Similarly, we did not find an endowment effect when we separated the sample on the basis of race, domestic/marital status, or number of siblings.

${ }^{65}$ See, for example, Shogren et al., supra note 19 (finding that the divergence of WTP and WTA value measures is persistent, even with repeated market participation and full information). Accord Jack L. Knetsch, The Endowment Effect and Evidence of Nonreversible Indifference Curves, 79 Am. Econ. Rev. 1277 (1989).

${ }^{66}$ Note that because the first round of the agency experiment nominated only a single wage, we cannot directly compare the first round of the agency experiments with the control (where a series of prices was nominated).
} 
TABLE 3

Random-EFFECTS LOGIT ON EARLy Rounds of AGENCY CONDITION

\begin{tabular}{lccc}
\hline \hline & Round 1 Only & Rounds 1 and 2 & Rounds 1, 2, and 3 \\
& $(1)$ & $(2)$ & $(3)$ \\
\hline$w_{\mathrm{h}}$ & .492 & .759 & .870 \\
Unendowed agent & $(.161)^{*}$ & $(.190)^{*}$ & $(.180)^{*}$ \\
& .799 & .575 & .274 \\
& $(.626)$ & $(.639)$ & $(.711)$ \\
\hline
\end{tabular}

NOTE. - The constant term is not reported. Standard errors are in parentheses.

* Significant at the $95 \%$ level.

plore this possibility, we reran the logit analysis reported in Table 1 (explicitly, specification (2)), but on a truncated data set consisting of only the first round, first two rounds, and first three rounds (respectively) of the agency experiment. ${ }^{67}$ Table 3 reports on these analyses.

Recall from Table 1 that the coefficient on the "unendowed" dummy in the eight-round case was equal to .3510971 with an insignificant standard error of .7366 . The results of Table 3 are largely consistent with these earlier results. Indeed, even when the analysis is limited to round 1 alone, unendowed subjects are not significantly more likely to pass up the mug for the money at any conventional significance level ( $p$-value $=.21)$. Limiting the analysis to the first two and the first three rounds, respectively, yielded results that were progressively similar to the full experiment. At the same time, even as the first-round analysis continues to give insignificant results, the results do appear to be slightly stronger than those of the full, eight-round analysis. This is, of course, consistent with the argument noted above that endowment effects can attenuate through learning. However, Table 3 suggests that at least within our agency condition, they appear to be starting from a relatively weak, statistically insignificant condition to begin with. ${ }^{6}$

Framing Effects. Finally, we considered a possible objection to the agency conditions in our study on the grounds that they introduce an unintended type of framing effect: subjects in the endowed agency condition were told that they had to choose between contributing their own mug and refusing to do so, while those in the unendowed agency condition were told that they must choose between to taking the firm's mug and abstaining. This added contextual detail, one might argue, may have inadvertently introduced a moral distinction between the actions of the subjects in the two conditions. Subjects who are predisposed toward altruism might feel greater anxiety over

${ }^{67}$ We did the same for truncated versions of the data set consisting of the first two, the first three, and the first four rounds.

${ }^{68}$ Of course, without gathering more data, it would be impossible to state with certainty whether the slight difference in protocols has a dispositive effect. There are other slight differences (such as the knowledge that only one of the eight rounds would count for final payoffs) that we cannot directly test. 
the prospect of taking the firm's mug than failing to contribute their own to the enterprise.

While we recognize this potential criticism, we remain relatively confident of our results for a number of reasons. Most immediately, the framing-effect concern tends to support our results instead of undercutting them. Indeed, the principal consequence of the framing effect described above would be to place the patina of moral blameworthiness on subjects who "took" the firm's mug, making them more reluctant to do so than subjects who already felt a sense of rightful ownership. One would therefore expect altruism would increase the differential between the endowed and unendowed subjects' valuations. Thus, had we detected an endowment effect among our agency subjects, this critique might render our results somewhat ambiguous, for we would not be able to identify whether the detected "wedge" separating the subjects was an artifact of endowment effects, framing effects, or some combination thereof. Given that we were unable to find such a wedge in the first place, however, the framing effect critique seems inapposite. ${ }^{69}$

Nevertheless, as a failsafe, we ran one additional experimental treatment (not reported upon in detail here) in which unendowed subjects were simply given the choice between accepting a contract that contained a low wage with a mug (and in which the firm would receive a low payoff) versus a contract that contained a high wage with no mug (in which the firm would receive a high payoff). Such an experimental design helps to remove the possible moral blameworthiness of taking the firm's mug. Comparing these unendowed agency "choosers" with our endowed agency subjects, we did not find evidence of a significant difference in valuations.

\section{Understanding the Results with an AdDitional Test}

The data from our agency conditions suggest that the business agency context has a significant effect on subjects' valuations, arguably bringing private valuation behavior in line with the predictions of rational choice theory. The obvious question is, why? This section posits two possible hypotheses and attempts to test between them using an additional experimental condition.

The Exchange-Value Hypothesis. The first possible explanation for our results, and the simplest, is that the agency context makes salient the "exchange value" of the mug rather than its consumption value, thereby causing subjects to treat it as a fungible good. This conjecture is consistent

\footnotetext{
${ }^{69}$ In addition, we deliberately designed the experimental materials to involve a rather "thin" and unembellished description of the firm. "Amalgamated Products" had no individual associated with it, and the consequences (if any) of a low payoff for the firm were never made salient to the experimental subjects. Given that our primary enterprise was to test for endowment effects (and not other-regarding preferences) within organizational environment, such an approach is entirely appropriate.
} 
with evidence that individuals do not endow goods that they view predominantly as trading goods or stores of value. ${ }^{70}$ It also is consistent with evidence that agents who repeatedly trade goods with uniqueness attributes (such as sports memorabilia) do not display significant endowment effects. ${ }^{71}$ Confirmation of this hypothesis would comprise additional evidence that the endowment effect does not depend simply on objective factors-such as the presence of thick markets-but also on psychological factors affecting whether the subject focuses on the exchange value or the consumption value of the good.

The Shared-Entitlement Hypothesis. A second possible explanation is that the organizational context blurs the distinction between the agent's own endowment and that of the firm (effectively substituting "our" in place of "my"). Viewed from this perspective, subjects who agreed to work for the firm knowing that the firm's profits depended on its ability to use the asset might come to view the firm as jointly entitled to the asset. Endowed subjects' ensuing sense of obligation to the firm might cause them to be less protective of their entitlement than they would be otherwise. Moreover, this sense of asset commingling could also make unendowed agents feel more entitled to claim a share of the firm's assets and thereby more likely to value the mug highly. Combined, these joint or "shared entitlement" effects would cause a convergence of WTP and WTA in the organizational context and could conceivably yield our agency results.

In order to assess which of these two hypotheses is most consistent with our results, we formulated an additional experiment designed to distinguish between them. In particular, in this experiment, we tested for the existence of endowment effects within an agency context that implicated the "exchange value" hypothesis, but in which the preconditions for the "shared entitlement" hypothesis were removed. We again did not find any evidence of a significant endowment effect, both confirming the results of our prior agency experiment and providing evidence consistent with the exchange-value hypothesis. ${ }^{72}$

\section{A. Detailed Description of the Exchange-Value Experiment}

The exchange-value experiment was fundamentally similar to the agency endowment experiment in its basic procedures. As before, we divided the subjects into two groups: endowed and unendowed. As before, the subjects were told that they were being recruited to be a manager for Amalgamated

${ }^{70}$ See note 34 supra.

${ }^{7}$ See List, supra note 32.

${ }^{72}$ By implication, then, our results also suggest that our findings in Section II are not driven by the fact that the mug was a potential factor of production. 
Products ${ }^{73}$ and were offered a choice between receiving a low wage coupled with a mug and receiving a higher wage and no mug. In this experiment, however, the subjects made this decision at the same time that they decided whether to work for the firm. Moreover, the subjects were not told that their choice would affect the firm's profits: the subjects simply could increase their monetary wage if they chose to contribute/reject the mug.

Specifically, both endowed and unendowed exchange-value subjects were told that, in each round, Amalgamated Products would make them an offer to work for it that consisted of a choice of one of two employment contracts. The unendowed subjects were told that "the two contracts will differ in the monetary amount offered and in whether or not the firm agrees to pay you a mug, in addition to a monetary wage." The endowed subjects were told that the "two contracts will differ in the monetary amount offered, depending on whether or not you agree to contribute your mug to the firm when you go to work for it." Each subject was then told that she would receive a $\$ 2$ wage if she took/kept the mug and a higher wage (ranging from $\$ 3$ to $\$ 15$ depending on the round) if she did not keep/take the mug. Each subject thus had three choices: reject both contracts and refuse to work for the firm for that round (in which case she would not get any monetary payoff) or agree to work for the firm and accept one of the two contracts. As before, subjects were told that one of the rounds would be selected at random at the end of the experiment and that each subject would receive the payoff that she obtained in that round.

The experimental instructions for this condition did not mention any impact of the mug on the firm's profits. Nor were subjects told that the mug could be used as a factor of production. Thus, the primary difference between this experiment and the control experiment is that subjects were placed in a business context in which the amount they were being offered for the mug took the form of wages for their services.

\section{B. The Results}

There were 76 subjects who participated in this experiment: ${ }^{74} 33$ endowed with a mug and 43 unendowed. Figure 4 presents an analysis of the relative frequency with which the endowed and unendowed subjects passed up possession of the mug, conditional on the high-wage offer. As in previous ex-

\footnotetext{
${ }^{73}$ Although they were informed that their job at the firm would be one of a "manager," these subjects were told nothing about any duties that such a job might entail (see the Appendix). This was done in order to minimize any potential effects of the shared-entitlement hypothesis. (It is, of course, possible that the very use of the term "manager" might itself trigger a sense of shared entitlement, although we conjecture that such an effect would require greater contextual richness than the use of a single word.)

${ }^{74} \mathrm{As}$ in our previous experiments, these subjects also were first-year law students who participated either in the summer before starting law school or in the first few weeks of the first semester. The payoffs and procedures were the same as the agency experiment.
} 


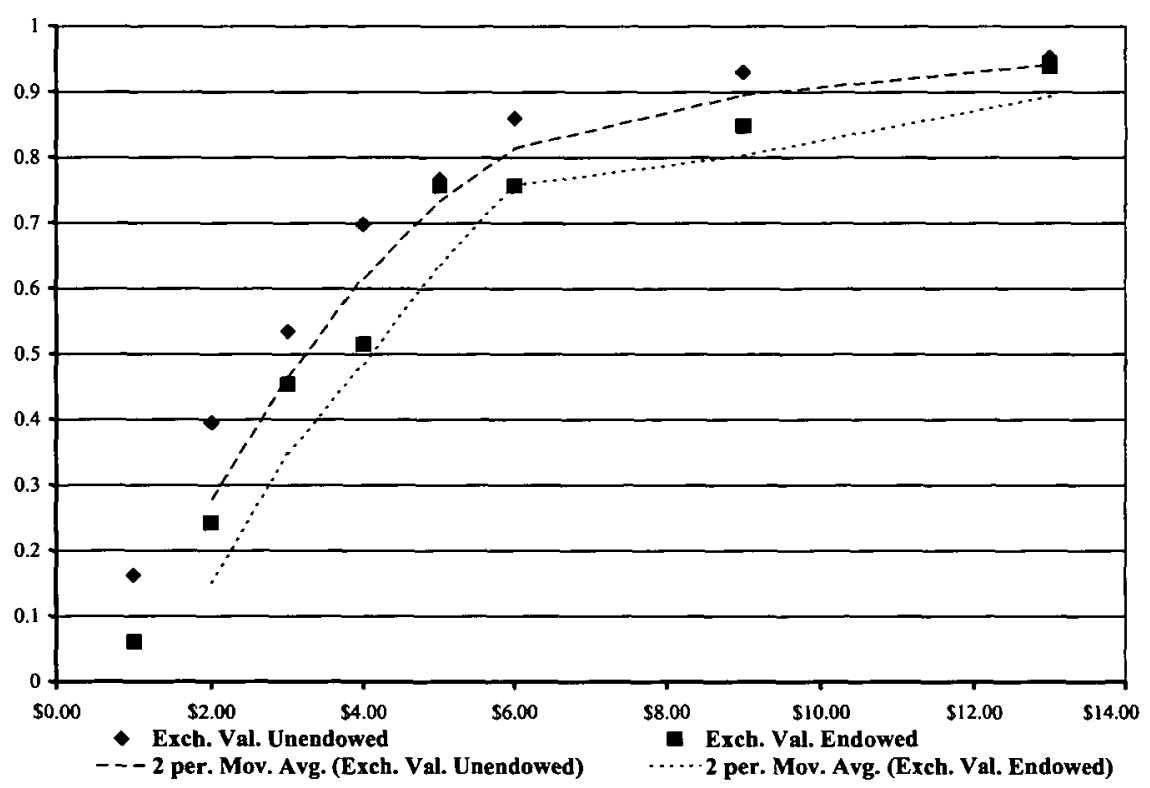

FIGURE 4.-Rate at which exchange-value subjects opted for money over mug. The horizontal axis denotes $w_{\mathrm{h}}-w_{\mathrm{l}}$.

periments, all subjects' preferences for money rather than the mug monotonically increase in the high-wage offer. This is consistent with the payoffs' being sufficiently large to motivate subjects to make meaningful choices; it also is consistent with subjects' understanding the experiment.

Visual examination of Figure 4 reveals evidence of a small WTP/WTA differential, but not one that is particularly economically significant. Endowed exchange-value subjects are slightly less likely to choose the mug over cash at each implied valuation level, but the effect appears minimal at any valuation level. And indeed, the mean valuation of endowed subjects (\$3.81) exceeded that of the unendowed subjects $(\$ 3.38)$ by $\$ .43$, approximately 27 percent of the observed difference in the control group of $\$ 1.57$. Moreover, as with the agency condition, the two samples display an identical median valuation of $\$ 3.00$.

A statistical comparison of the mean valuations indicates that this numerical difference not only is economically modest but also is statistically insignificant (one-sided $t$-test, $p=.252, \mathrm{df}=65$ ). Likewise, a nonparametric two-sample Wilcoxon rank-sum test fails to reject the null hypothesis of distributional symmetry $(z=.68, p=.49)$, though less emphatically than in the agency condition. 


\section{Discussion}

These results are largely consistent with the hypothesis that situating subjects in an agency context mutes the endowment effect because the subjects focus on the exchange value of the entitlements for trade.

Our conclusion that our agency experiment results were primarily a product of "exchange-value" effects, not "shared-entitlement" explanations, is supported by some of the literature on other-regarding preferences, which suggests that subjects would have been unlikely to manifest significant otherregarding preferences in the context of our experiment. The possibility that agents might manifest other-regarding behavior toward their principals motivated the "shared-entitlement" hypothesis. Yet the evidence on otherregarding behavior also suggests that subjects would be unlikely to manifest it in the context of our experiment. For example, although there is evidence involving "Dictator" games ${ }^{75}$ that shows that Dictators do share a portion of the available surplus, ${ }^{76}$ when Dictators are told that the two players are in a "buyer" and "seller" relationship, they are significantly more selfish. ${ }^{77}$ In addition, the evidence suggests that subjects are particularly disposed to be other-regarding with regard to a known recipient with whom they have had contact and are much less disposed to be other-regarding with regard to an unknown person. ${ }^{78}$ Thus, a fictitious profit-maximizing com-

${ }^{75}$ A Dictator game is one in which one subject is given a specific amount of money (such as \$1) and told she can share as much (or as little) of it as she likes with the other player.

${ }^{76}$ See, for example, Robert Forsythe et al., Fairness in Simple Bargaining Experiments, 6 Games \& Econ. Behav. 347 (1994). This is in apparent contrast with the presumptions of many law and economics scholars. Although nothing in economic theory preordains it, conventional law and economics generally defines "self-interest" rather myopically, giving rather scant attention to other-regarding preferences (or "ORPs") such as guilt, altruism, or other independent motivations for interpersonal faimess. Some theorists have suggested that the evidence of otherregarding behavior is simply an artifact of experimental observation-of people's desire to appear "fair" to the experimenters in a low-stakes situation-and people do not exhibit otherregarding behavior in the real world. The existing evidence, however, does not support this hypothesis: although experimenter observation does affect other-regarding behavior, subjects manifest ORPs even in "double-blind" Dictator games in which neither the other experimental subject nor the experimenter would know of the Dictator's decision. See, for example, Hoffman et al., supra note 31 ; see also Gary E. Bolton \& Rami Zwick, Anonymity versus Punishment in Ultimatum Bargaining, 10 Games \& Econ. Behav. 95 (1995).

${ }^{77}$ Hoffman et al., supra note 31 , at 357 , table II. Similarly, players in Ultimatum Games-in which the first player is given money and told she can share as much as she likes with the other, but where the other can reject the offer, in which case neither player gets anything-display significant evidence of other-regarding behavior in many circumstances. Nevertheless, when subjects are told at the outset to maximize their winning, the first players generally make minimal offers to share with the other player. Binmore, Snaked, \& Sutton, supra note 34. For a discussion of this experiment see Thaler, supra note 5, at 26-27.

${ }^{78}$ For example, Iris Bohnet and Bruno Frey ran a set of experiments involving three versions of the Dictator game: (1) the Dictator and recipient did not know each other's identity, (2) the Dictator and recipient look at each other (so they can identify each other) but do not speak, and (3) the Dictator and recipient may speak with each other, face to face, but may not make a binding contract. They found that while the Dictator allocated, on average, one-quarter of the initial endowment to the recipient in the first version of the game, the second and third 
pany-Amalgamated Products--with no human representative would appear to be a particularly unlikely subject of other-regarding sentiment, given the existing evidence. ${ }^{79}$

Nevertheless, although our results suggest that the exchange-value condition is sufficient to mute endowment effects-even absent other-regarding "shared entitlement" concerns-our results do suggest some role for such other-regarding preferences, albeit only a weak one. For example, a comparison of the imputed valuations of the exchange-value subjects with those of the agency subjects reveals that the exchange-value subjects valued the mug on average more than the agency subjects. Specifically, the mean valuation of the exchange-value subjects was $\$ 3.57$, which is $\$ .54$ larger than the mean valuation of the agency subjects of $\$ 3.03$. This suggests that agency subjects' concerns for the firm may cause both endowed and unendowed subjects to value the mug less-while not necessarily affecting the differential value between them. Nevertheless, in the context of our experiment, this effect is relatively weak: the $\$ .54$ difference is not only modest numerically but statistically different from zero only at relatively weak significance levels (one-sided $t$-test, $p=.098, \mathrm{df}=142$; two-tailed $t$-test, $p=.193$, $\mathrm{df}=$ 142). This basic finding emerges from more complicated regression analyses as well (which we therefore omit in the current analysis). Given the purely fictitious nature of our firm, our finding of some evidence consistent with other-regarding behavior even in this context suggests that further exploration of other-regarding preferences in the business context may be warranted. ${ }^{80}$

treatments produced virtually even splits and were statistically indistinguishable from one another. Iris Bohnet \& Bruno S. Frey, The Sound of Silence in Prisoner's Dilemma and Dictator Games, 38 J. Econ. Behav. \& Org. 43 (1999); Iris Bohnet \& Bruno S. Frey, Social Distance and Other-Regarding Behavior in Dictator Games: Comment, 89 Am. Econ. Rev. 335 (1999). Bohnet and Frey seem to find more sharing in the anonymous condition than do Hoffman $e t$ al., supra note 31 . However, the experimental protocols are not given with enough specificity to allow the reader to conclude whether or not the results are inconsistent.

${ }^{79}$ This is not to say that people do not manifest other-regarding preferences toward institutions. For example, Catherine Eckel and Philip Grossman compared willingness to donate to ordinary recipients versus the American Red Cross and found that Dictators allocated on average only 10 percent of their payoffs to the ordinary subject recipients but allocated 31 percent of their payoffs to the American Red Cross. Catherine C. Eckel \& Philip J. Grossman, Altruism in Anonymous Dictator Games, 16 Games \& Econ. Behav. 181, 187 (1996). Nevertheless, this evidence is consistent with subjects' preferring known and worthy recipients to those they are not familiar with. Amalgamated Products was neither a charitable organization nor one that was known to the subjects (since it is a fictitious company).

${ }^{80}$ For example, there is evidence of other-regarding preferences in the agency context when the principal is an individual rather than a company. See, for example, Vital Anderhub, Simon Gächter, \& Manfred Königstein, Efficient Contracting and Fair Play in a Simple PrincipalAgent Experiment (Working Paper No. 18, Univ. Zurich, Inst. for Empirical Res. Econ., August 1999); W. Guth et al., Fairness within Firms: The Case of One Principal and Multiple Agents (Working paper, Humboldt Univ. Berlin 1999); W. Guth et al., An Experimental Study of a Dynamic Principal-Agent Relationship, 19 Managerial \& Decision Econ. 327 (1998); see also Ernst Fehr, Simon Gächter, \& Georg Kirchsteiger, Reciprocity as a Contract Enforcement Device-Experimental Evidence, 65 Econometrica 833 (1997); Claudia Keser \& Marc Willinger, Principals' Principles When Agent Actions Are Hidden, 18 Int'l J. Indus. Org. 163 


\section{Conclusion}

Behavioral law and economics has considerable potential implications for the study of corporate law. Yet scholars' efforts to analyze corporate law from this perspective have been hampered by considerable uncertainty about whether behavioral phenomena identified in context of individual decision making persist in the corporate context. This article has attempted to take an initial step toward a more systematic application of behavioral law and economics to company law by inquiring into the robustness of a well-known cognitive bias-the endowment effect-within an agency relationship. We find that in the introducing a business agency relationship tends to dampen (and virtually eliminate) this effect.

There are several possible implications of our results, both for the study of business organizations and for behavioral law and economics generally. Specifically, our results suggest that the nexus of relationships often identified with "the firm" may operate (at least in part) as a debiasing mechanism, thereby representing an underappreciated consequence of organizing trade within firms. ${ }^{81}$ Of course, just as the business environment mutes some behavioral biases (such as the endowment effect), it could certainly exacerbate others. Thus, increased attention to cognitive biases by corporate scholars seems to be warranted. ${ }^{82}$

In addition, our results highlight a broader message concerning the relationship between normative policy analysis and experimental research. Reform proposals, by their very nature, tend to be sweeping and general, implicating large populations in highly heterogeneous environments. By contrast, experimental research is necessarily constrained within a specific, controlled environment, purposely isolated from other aspects of the real world. This isolation is both its great strength and its profound weakness. Observing a predictable behavioral pattern within a controlled experimental setting enables researchers to make causal claims with minimal fear that unobserved phenomena or reverse causality are driving their results. Yet this very controlled setting makes it difficult to generalize to real-world settings that are the focus of policy reform proposals. To be sure, we as a society must sometimes make difficult policy choices even in a world of imperfect

(2000). Of course, care also must be taken before developing policy conclusions for corporate law based on other-regarding preferences because these also are highly context dependent. See generally Arlen, supra note 11, at 1785-87.

${ }^{81}$ See, for example, Roberta Romano, A Comment on Information Overload, Cognitive Illusions, and Their Implications for Public Policy, 59 S. Cal. L. Rev. 313 (1986).

${ }^{82}$ See Langevoort, Organized Illusions, supra note 4 . Indeed, given the context dependency of endowment effects, we cannot say that we have shown that subjects would invariably fail to manifest endowment effects in the aggregate. Under different conditions (for example, a different asset), subjects might manifest endowment effects. The central message of our results is that scholars cannot simply assume that behavioral results found in outside the agency context are present within the agency context. 
empirical knowledge. Nonetheless, that informational constraint should also not lead us to ascribe undue explanatory power to any methodological paradigm, be it economics, psychology, behavioral law and economics, or something else.

\section{APPENDIX}

\section{SubJeCt INSTRUCTIONS}

\section{A. Agency Experiment: Endowed Subjects}

If you proceed with the experiment, you will be given a USC mug, which can be purchased at the campus bookstore.

The central purpose of the experiment is to examine decision making by managers of corporations. You are to assume that you are being recruited by a large consumer marketing firm, Amalgamated Products Corporation, which is seeking a manager for a new marketing project. Amalgamated will offer to pay you for your managerial services. Should you accept its offer, the project you are to manage will produce a monetary payoff for the firm, which could consist of either a low payoff or a high payoff, an outcome that depends on actions you take as manager. Specifically, the success of the project depends on whether you contribute your mug to the project: if you contribute your mug, the project will produce a high payoff for the firm; if you do not, it will produce a low payoff for the firm.

In each round of the experiment, a representative from Amalgamated Products will offer you a contract to work for the firm in exchange for money. The amount the representative of the firm offers to pay you may depend on whether the project yields a low payoff or a high payoff. Alternatively, the representative may offer to pay you a fixed amount of money regardless of whether the project eventually yields a low payoff or a high payoff. You may accept or reject the firm's offer as you see fit. All offers are made on a take-it-or-leave-it basis and are good only for the round in which they are made. There is no bargaining. Thus, if you reject the representative's offer, the round will end immediately, and your personal payoff for that round will consist solely of your mug. You will indicate your acceptance or rejection on the sheet of paper that states the offer.

Should you accept the firm's offer, you will become the manager of the project. You will then be asked to make a choice between contributing your mug to the project or keeping it for yourself. This decision is strictly yours. Indeed, regardless of your choice, the firm must pay you whatever wage it offered you. However, as previously stated, your decision about whether to contribute your mug determines whether the project yields a high payoff or a low payoff.

You will indicate your choice of whether to contribute your mug on a sheet of paper that you will return to the experimenter. Your personal payoff for the round can then be determined. Your personal payoff for the round will consist of whatever the firm owes you (depending on whether it was a high-payoff or low-payoff project), plus your mug (if you had decided to keep it instead of contributing).

You will play eight rounds of this experiment (in addition to two practice rounds), for a total of approximately 1 hour. The terms of the contract you are offered will vary from round to round and do not depend on anything that happened in any previous round. Your additional compensation (if any) for participating in the experiment will be based on the outcome of one out of the eight rounds of the experiment. In particular, at the end of the experiment, the experimenter will use a random process to determine which of the eight rounds counts for everyone. You will then be paid whatever you earned in that round. For example, if the random process were 
to select round 1 , and if in round 1 you had rejected the firm's contract, your payoff would consist solely of $\$ 5$ plus a mug. Alternatively, if the random process were to select round 4 , and if in round 4 you had agreed to a contract paying you a flat wage of $\$ 2$, and if you decided to keep your mug, your total compensation would be $\$ 7$ $(=\$ 5+\$ 2)$ plus the mug. Or, if the random process were to select round 2 , and if in round 2 you had agreed to a contract paying you a wage of $\$ 2$ for a low payoff and $\$ 8$ for a high payoff, and if you decided to contribute your mug, your total compensation would be $\$ 13(=\$ 5+\$ 8)$ and no mug. You will begin each round with your original mug, even if you had chosen to contribute it in the previous round.

\section{B. Agency Experiment: Unendowed Subjects}

The central purpose of the experiment is to examine decision making by managers of corporations. You are to assume that you are being recruited by a large consumer marketing firm, Amalgamated Products Corporation, which is seeking a manager for a new marketing project. Amalgamated will offer to pay you for your managerial services. Should you accept its offer, the project you are to manage will produce a monetary payoff for the firm, which could consist of either a low payoff or a high payoff, an outcome that depends on the actions you take as manager.

Specifically, the success of the project depends on whether a mug the firm owns is used in the project: the project will yield a high payoff for the firm if the mug is used and a low payoff if the mug is not used for the project.

In each round of the experiment a representative from Amalgamated Products will offer you a contract to work for the firm during that round in exchange for money. The representative may offer to pay you one amount if the project generates a low payoff for the firm and a different amount if the project generates a high payoff. Alternatively, the representative may offer you a fixed amount of money regardless of whether the project eventually yields a low payoff or a high payoff for the firm. You may accept or reject the representative's offer as you see fit. All offers are made on a take-it-or-leave-it basis and are good only for the round in which they are made. There is no bargaining. If you reject the representative's offer, the round will end immediately for you, and your payoff for that round will consist of nothing. ( $\mathrm{Be}$ aware, however, that a rejected offer still "counts" as one of the rounds you played.) You will indicate your acceptance or rejection of the proposal on the sheet of paper that states the offer.

Should you accept the representative's offer, you will become the manager of the project. As manager, you will have exclusive access to some of the firm's property (and, in particular, the mug). This access affords you the opportunity to take the firm's mug for yourself rather than leave it to be used as an input for the project. Indeed, regardless of your choice, the firm must pay you whatever wage it offered you. However, your decision about whether to take the firm's mug determines whether the project yields a high payoff or a low payoff.

You will indicate your decision as to whether to take the mug on a sheet of paper and return it to the experimenter. This will determine whether the project yields a low payoff or a high payoff and, thus, what the firm owes you. Your personal payoff for the round, therefore, will consist of whatever the firm owes you, plus the mug (if you had decided to take it).

You will play eight rounds of this experiment (in addition to two practice rounds), for a total of approximately one hour. [Similar instructions to those above follow.]

\section{Exchange-Value Experiment: Unendowed Subjects}

The central purpose of the experiment is to examine decision making by managers of corporations. You are to assume that you are being recruited by a large consumer 
marketing firm, Amalgamated Products Corporation, which is seeking a manager for a new marketing project. Amalgamated will offer to pay you for your managerial services. In each round of the experiment, a representative from Amalgamated Products will give you a proposal to work for the firm during that round. The proposal will give you a choice of one of two employment contracts. The two contracts will differ in the monetary amount offered and in whether or not the firm agrees to pay you a mug, in addition to a monetary wage.

All offers are made on a take-it-or-leave-it basis. There is no bargaining. You have three choices. You may reject both contracts and refuse to work for the firm for that round. If you do this, the round will end immediately for you, and your payoff for that round will consist of nothing. (Be aware, however, that a rejected offer still "counts" as one of the rounds you played.) Alternatively, you may agree to work for the firm and accept one of the two contracts. You will indicate your choice on the sheet of paper that states the offer and return it to the experimenter.

Your choice will determine what the firm owes you. Your personal payoff for the round, therefore, will consist of whatever money the firm owes you, plus the mug (if you had decided to accept the contract that gave you a mug.)

You will play eight rounds of this experiment (in addition to two practice rounds), for a total of approximately 1 hour. The terms of the contracts you are offered will vary from round to round and do not depend on anything that happened in any previous round. Your additional compensation for participating in the experiment (if any) will be based on the outcome of one out of the eight rounds of the experiment. In particular, at the end of the experiment, the experimenter will use a random process to determine which of the eight rounds counts for everyone. You will then be paid whatever you earned in that round. For example, if the random process were to select round 1 , and if in round 1 you had rejected the firm's contracts, your payoff would consist of nothing, so your total compensation would be your $\$ 5$ initial payment. Alternatively, if the random process were to select round 4 , and if in round 4 you had agreed to a contract paying you a flat wage of $\$ 2$ and a mug, your total compensation would be $\$ 7(=\$ 5+\$ 2)$ plus the mug. Alternatively, if the random process were to select round 2 , and if in round 2 you had agreed to a contract paying you a wage of $\$ 8$ and no mug, your total compensation would be $\$ 13(=\$ 5+\$ 8)$ and no mug.

\section{Exchange-Value Experiment: Endowed Subjects}

At the beginning of the experiment, you will be given a USC mug, which can be purchased at the campus bookstore.

The central purpose of the experiment is to examine decision making by managers of corporations. You are to assume that you are being recruited by a large consumer marketing firm, Amalgamated Products Corporation, which is seeking a manager for a new marketing project. Amalgamated will offer to pay you for your managerial services.

In each round of the experiment, a representative from Amalgamated Products will give you a proposal to work for the firm as a manager during that round. The proposal will give you a choice of one of two employment contracts. The two contracts will differ in the monetary amount offered, depending on whether or not you agree to contribute your mug to the firm when you go work for it. Specifically, the firm will offer you $\$ 2$ to work for the firm if you retain your mug; the firm will offer you a higher wage if you agree to work for them and contribute your mug to the firm, with the amount ranging from $\$ 3$ to $\$ 15$. All offers are made on a take-it-orleave-it basis. There is no bargaining.

Thus, you have three choices. You may reject both contracts and refuse to work 
for the firm for that round. If you do this, the round will end immediately for you, and your payoff for that round will consist of nothing. (Be aware, however, that a rejected offer still "counts" as one of the rounds you played.) Alternatively, you may agree to work for the firm and accept one of the two contracts. You will indicate your choice on a sheet of paper that you will return to the experimenter. Your choice will determine what the firm owes you for that round. Your personal payoff for the round, therefore, will consist of whatever money the firm owes you, plus the mug (if you had decided to accept the $\$ 2$ wage contract and retain your mug).

You will play eight rounds of this experiment (in addition to two practice rounds), for a total of approximately 1 hour. [Similar instructions to those above follow.] 
